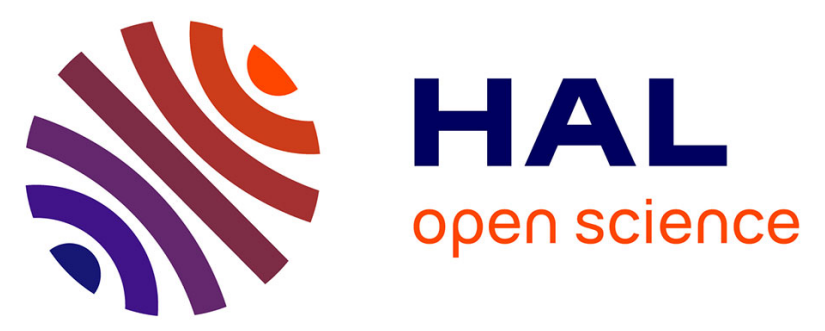

\title{
Pre-explosive conduit conditions of the 1997 Vulcanian explosions at Soufrière Hills Volcano, Montserrat: II. Overpressure and depth distributions
}

\author{
Alain Burgisser, Laurent Arbaret, Timothy H. Druitt, Thomas Giachetti
}

\section{To cite this version:}

Alain Burgisser, Laurent Arbaret, Timothy H. Druitt, Thomas Giachetti. Pre-explosive conduit conditions of the 1997 Vulcanian explosions at Soufrière Hills Volcano, Montserrat: II. Overpressure and depth distributions. Journal of Volcanology and Geothermal Research, 2011, 199 (3-4), pp.193-205. 10.1016/j.jvolgeores.2010.11.014 . insu-00551314

HAL Id: insu-00551314

https://hal-insu.archives-ouvertes.fr/insu-00551314

Submitted on 26 Jan 2011

HAL is a multi-disciplinary open access archive for the deposit and dissemination of scientific research documents, whether they are published or not. The documents may come from teaching and research institutions in France or abroad, or from public or private research centers.
L'archive ouverte pluridisciplinaire HAL, est destinée au dépôt et à la diffusion de documents scientifiques de niveau recherche, publiés ou non, émanant des établissements d'enseignement et de recherche français ou étrangers, des laboratoires publics ou privés. 
Pre-explosive conduit conditions of the 1997 Vulcanian explosions at Soufrière Hills

Volcano, Montserrat: II. Overpressure and depth distributions

Alain BURGISSER ${ }^{\mathrm{a}^{*}}$, Laurent ARBARET ${ }^{\mathrm{a}}$, Timothy H. DRUITT ${ }^{\mathrm{b}, \mathrm{c}, \mathrm{d}}$, Thomas

GIACHETTI $^{\mathrm{b}, \mathrm{c}, \mathrm{d}}$

${ }^{\text {a } I n s t i t u t ~ d e s ~ S c i e n c e s ~ d e ~ l a ~ T e r r e ~ d ' O r l e ́ a n s, ~}$

CNRS/INSU, Université d'Orléans, Université François Rabelais - Tours

1A rue de la Férolerie

45071 Orléans cedex 2 (France)

${ }^{\mathrm{b}}$ Clermont Université, Université Blaise Pascal, Laboratoire Magmas et Volcans, BP 10448,

F-63000 CLERMONT-FERRAND

${ }^{\mathrm{c}}$ CNRS, UMR 6524, LMV, F-63038 CLERMONT-FERRAND

d IRD, R 163, LMV, F-63038 CLERMONT-FERRAND

Abstract: 375 words, Main text: 7400 words, 2 Tables, 9 Figures.

* Corresponding author: Tel: +33 (0)238 2553 89. Fax: +33 (0) 2386364 88. Email: burgisse@cnrs-orleans.fr 


\section{Abstract}

A type example of Vulcanian eruptive dynamics is the series of 88 explosions that occurred between August and October 1997 at Soufrière Hills volcano on Montserrat Island. These explosions are interpreted to be caused by the pressurization of a conduit by a shallow highly crystalline and degassed magma plug. We test such an interpretation by combining the pressures and porosities of the pre-explosive magma column proposed by Burgisser et al. (2010, doi:10.1016/j.jvolgeores.2010.04.008) into a physical model that reconstructs a depthreferenced density profile of the column for four mechanisms of pressure buildup. Each mechanism yields a different overpressure profile: 1) gas accumulation, 2) conduit wall elasticity, 3) microlite crystallization, and 4) magma flowage. For the three first mechanisms, the three-part vertical layering of the conduit prior to explosion was spatially distributed as a dense cap atop the conduit with a thickness of a few tens of meters, a transition zone of 400$700 \mathrm{~m}$ with heterogeneous vesicularities, and, at greater depth, a more homogeneous, lowporosity zone that brings the total column length to $\sim 3.5 \mathrm{~km}$. A shorter column can be obtained with mechanism 4: a dense cap of less than a few meters, a heterogeneous zone of 200-500 m, and a total column length as low as $2.5 \mathrm{~km}$. Inflation/deflation cycles linked to a periodic overpressure source offer a dataset that we use to constrain the four overpressure mechanisms. Magma flowage is sufficient to cause periodic edifice deformation through semi-rigid conduit walls and build overpressures able to trigger explosions. Gas accumulation below a shallow plug is also able to build such overpressures and can occur regardless of magma flowage. The concurrence of these three mechanisms offers the highest likelihood of building overpressures leading to the 1997 explosion series. We also explore the consequences of sudden (eruptive) overpressure release on our magmatic columns to assess the role of syn-explosive vesiculation and pre-fragmentation column expansion. We find that large shallow overpressures and efficient syn-explosive vesiculation cause the most dramatic 
pre-fragmentation expansion. This leads us to depict two end-member pictures of a Vulcanian explosion. The first case corresponds to the widely accepted view that the downward motion of a fragmentation front controls column evacuation. In the second case, syn-explosive column expansion just after overpressure release brings foamed-up magma up towards an essentially stationary and shallow fragmentation front.

Keywords: Soufrière Hills Volcano; Montserrat;Vulcanian explosions; decompression; conduit modeling 


\section{Introduction}

Vulcanian eruptions are generally short-lived (seconds to minutes) explosions that result from brutal decompression of a sealed conduit containing pressurized magma and that eject relatively small volumes of material (Self et al., 1979; Woods, 1995; Stix et al., 1997; Sparks et al., 1997; Morrissey and Mastin, 2000). These violent events are generally periodic and have been linked to a combination of pressure buildup within the magmatic conduit and the existence of a critical pressure threshold above which explosion starts (Hoblitt et al., 1996). Sealing of the conduit by juvenile material occurs by exsolution and syneruptive degassing of volatiles under open system conditions from magma at shallow levels (e.g., Eichelberger et al., 1986). This exsolution has a double effect on the magma: it increases melt viscosity and thus stiffens the plug, and it induces crystallization, which also increases bulk magma viscosity by addition of microlites. The degassed and crystalline plug results in pressurization of the underlying magma in the conduit. If the plug forces the magmatic column below to react as a closed system, large quantities of gas can accumulate over a short period of time just below the plug. If the column remains long enough a closed system with respect to gas, decompression-driven crystallization can also cause pressure buildup (Tait et al., 1989; Sparks, 1997; Stix et al., 1997; Hammer et al., 1999). If the plug fails to fully seal the column below, there are two other mechanisms able to induce conduit pressurization. First, the elasticity of the conduit walls may attempt to reestablish a lithostatic gradient in the conduit (e.g., Mitchell, 2005). Second, the interaction between magma ascent within the conduit and the stiffening of the plug may generate a non-linear vertical pressure gradient (Sparks, 1997; Voight et al., 1999; Wylie et al., 1999; Diller et al., 2006; Clarke et al., 2007). Beyond making the magma more prone to fragmentation (Gardner et al., 1996; Spieler et al., 2004), the exsolved gas phase subjected to these pressurization mechanisms is capable of driving the powerful Vulcanian jet (e.g., Wilson, 1980; Woods, 1995; Clarke et al., 2002). 
Plug formation and magma column pressurization thus involve at least four independent mechanisms that condition the magma column just prior to a Vulcanian explosion. Here we use the precise knowledge of the state of the magmatic column just before a Vulcanian explosion to assess the role of each mechanism, and to approach the inner workings of Vulcanian explosions. We focus on the series of 88 Vulcanian explosions that occurred with recurrence intervals of $\sim 10$ hours between August and October 1997 at Soufrière Hills volcano on Montserrat Island (Young et al., 1998; Druitt et al., 2002). Each explosion started with a high-flux phase that lasted several tens of seconds, involving the discharge of on average $3 \times 10^{5} \mathrm{~m}^{3}$ of magma, about one third forming fallout and two thirds forming pyroclastic flows and surges (Druitt et al., 2002). A well-documented eruptive sequence, and a wealth of information on the dynamics of these explosions (Formenti et al., 2003; Formenti and Druitt, 2003; Clarke et al., 2002, 2007; Kennedy et al., 2005; Diller et al., 2006; Giachetti et al., 2010; Burgisser et al., 2010), have contributed to establishing this Vulcanian episode as a reference, and the reader is referred to these papers for full details.

We build on the work of Burgisser et al. (2010), who have estimated the vertical magma density profile in the conduit immediately prior to an average 1997 Vulcanian explosion by 1) documenting the textures covering the range of the 1997 products, 2) quantitative analysis of water content in interstitial glasses, and 3) combining these data with a simple model linking pre- and post-explosive vesicularities. This leads to a pressurereferenced density profile characterized by a three-part vertical layering of the conduit prior to explosion. This broad layering is based on the occurrence of five lithologies in the ejecta (glassy to crystalline dense clasts, breadcrusted bombs, texturally heterogeneous pumices, texturally homogeneous pumices, and homogeneous pumices from fallout deposits). A dense and strongly degassed plug caps the column. It is underlain by a shallow (up to $10 \mathrm{MPa}$ ) transition zone featuring complex mingling between vesicular and dense magma. At greater 
pressures (up to $85 \mathrm{MPa}$ ) and depths lies a more homogeneous zone of relatively dense (10-20 vol\% porosity) magma, of which all but the lowermost part was emplaced under partly open system degassing.

The present study combines the pre-explosive pressures and porosities proposed by Burgisser et al. (2010) into a physical model that reconstructs a depth-referenced density profile of the column for each respective mechanism of pressure buildup. We assess the four buildup mechanisms, each with a different overpressure profile: 1) gas accumulation, 2) conduit wall elasticity, 3) microlite crystallization, and 4) magma flowage. We use evidence from geodetic measurements that quantify periodic inflation/deflation cycles of the volcanic edifice to help us constrain the role of each mechanism at Soufrière Hills. We finally explore the consequences of sudden overpressure release on the obtained density profile.

\section{Method to convert pre-explosive pressures to depths}

Pre-explosive pressures can be converted to pre-explosive depths if a precise estimate of the vertical density distribution of the magmatic column is available. Clarke et al. (2007) considered that the average magma density in the column corresponded to an average clast density of $1500 \mathrm{~kg} / \mathrm{m}^{3}$. Clasts from our sampling have an average density of $1600 \mathrm{~kg} / \mathrm{m}^{3}$, which is comparable to that of Clarke et al. (2007). The main drawback of such an approach, however, is that it overlooks the fact that the true density profile is not linear with depth. We thus propose a physics-based method to combine pre-explosive pressures and porosities to infer the pre-explosive conduit density profile. Our starting dataset is that of Burgisser et al. (2010), which consists of pre-explosive pressures, vesicularities and water contents of 57 samples (Table 1). These values are outputs from a two-stage degassing model that takes into account gas expansion by decompression, water exsolution, and outgassing from clast 
interiors to their surroundings. We use their model outputs with the attached errors as a basis for our depth conversions.

Reconstruction of the pre-explosive conduit density profile can be carried out by considering the magmatic column to be made of a stack of horizontal slices, each of thickness $\Delta z_{i}$ and bulk density $\rho_{i}$ (Fig. 1). The sudden release of overpressure is a common explanation of Vulcanian explosions (Morrisey and Mastin, 2000), which has been invoked by many authors to explain the 1997 Vulcanian series at Soufrière Hills (e.g., Druitt et al., 2002; Melnik and Sparks, 1999, 2002; Formenti et al., 2003; Diller et al., 2006). The novelty of our model is to explicitly take into account that overpressure for each slice. The total pressure, $P_{i}$, at the base of a given slice is then:

$$
P_{i}=\rho_{i} g \Delta z_{i}+\Delta P_{i}+P_{i-1}
$$

where $g$ is gravitational acceleration, $\rho_{i} g \Delta z_{i}$ is magmastatic pressure exerted by slice i, $P_{i-1}$ is the pressure of the slice immediately above, and $\Delta P_{i}$ is the overpressure of that slice relative to the magmastatic value. If we further assume that each of the 57 samples represents one slice, its bulk density is:

$$
\rho_{i}=\alpha_{i} \rho_{g}+\left(1-\alpha_{i}\right) \rho_{m}
$$

where $\rho_{m}=\sim 2450 \mathrm{~kg} / \mathrm{m}^{3}$ is the bubble-free magma density at $850{ }^{\circ} \mathrm{C}$ (Devine et al., 2003) using Conflow (Mastin, 2002) and $\rho_{g}$ is the gas density at $P_{i}$ using the ideal gas law $\left(\rho_{g}=M P_{i} / R T\right.$ with $M=0.018 \mathrm{~kg} / \mathrm{mol}, R=8.3144 \mathrm{~J} / \mathrm{mol} / \mathrm{K}$, and $\left.T=1123 \mathrm{~K}\right)$. Pressures, $P_{i}$, and vesicularities, $\alpha_{i}$, are taken from our companion paper (Table 1, Burgisser et al., 2010). If the overpressures $\Delta P_{i}$ are known, Equs. (1) and (2) can be solved iteratively by using, in our case, the Newton-Rhapson method to obtain $\Delta z_{i}$ for each successive slice starting from atmospheric pressure at the vent. 


\subsection{Mechanism 1: Overpressure generated by gas accumulation}

The pre-explosive magma column has been shown to contain less water than was present in the reservoir, which implies that most of the evacuated column was permeable to gas leakage (Burgisser et al., 2010). Since water exsolution can occur over short timescales (Giachetti et al., 2010), sudden plug formation would cause a complex redistribution of porosity by gas transfer. Gas would leak from depth, driven by the magmastatic pressure gradient, and would accumulate below the plug. The resulting pressure rise just below the plug would in turn partially re-dissolve the incoming gas because of the increased solubility. Even with the simplification that sealing is instantaneous and causes the magma below to react as a closed system, modeling such a dynamic process is beyond the scope of this paper. The main obstacle is that the effects of plug formation cannot uniquely be linked to our pressure-referenced porosity distribution because 1) gas accumulation can only be modeled when each slice has a tightly constrained depth, which is unknown and 2) our pressure data are based on the assumption that the water content of the melt is at the saturation value, which is violated as long as the melt is not re-equilibrated with the accumulated gas.

Instead, we opt for decoupling the overpressure caused by gas accumulation and its effect on the depth distribution of the magma column. Such decoupling means that gas leakage is assumed to occur without affecting the porosity distribution of the column. In other words, we neglect the increased solubility caused by overpressure, but also the possible porosity reduction at depth caused by gas transfer to upper levels. An implication of this endmember situation is that magma is constrained by the conduit such that foam collapse is impossible. As a result, the pressure gradient is kept at the magmastatic level in Equ (1) to calculate the depth of each slice. Ignoring foam collapse has for effect to maximize the thickness of each slice, hence producing the longest magmatic column possible. 
To establish a decoupled overpressure profile, we first calculate the thickness of each slice by fixing $\Delta P_{i}=0$ in Equ (1). We then reattribute an overpressure to each slice so that the total pressure has a stair-step shape (Fig. 2 inset). The plug is a thin region in the conduit above which the pressure gradient is magmastatic and below which a vertical pressure gradient builds up with time by gas accumulation. In other words, gas leakage creates an overpressure above magmastatic that brings a section of the conduit below the plug to a constant total pressure. At most, this total pressure equals the tensile strength of the plug. Just prior to plug rupture, the magma below the plug is at constant pressure until the depth at which magmastatic load becomes greater than this constant pressure. We define this constant pressure as the plug pressure, and the difference between the plug pressure and the magmastatic value as the gas overpressure.

Gas overpressure depends on two free parameters: plug depth and plug pressure. As mentioned, plug pressure has to be sufficient to overcome the tensile strength of the plug, which highly depends on pre-explosive porosity. Plug strength can be estimated to be 16-31 MPa for the dense cap, and 2-54 MPa for the heterogeneous transitional zone (Burgisser et al., 2010). Even if we assume that gas transfer within the column does not affect porosity distribution in a major way, it is reasonable to consider that gas accumulation is consistent with observed small scale textural heterogeneities such as variable porosities. This textural criterion suggests that the plug extends at least to the base of the dense upper cap and at most to the base of the heterogeneous zone.

\subsection{Mechanism 2: Overpressure generated by conduit wall elasticity}

Conduit walls are likely to exert some strain on the magmatic column. The consideration of this source of overpressure is motivated by an interpretation of deformation 
measurements suggesting that conduit walls are not fully rigid and react to pressure changes within the magma column. Widiwijayanti et al. (2005) showed that dome collapse not only causes inflation of the volcano by mass removal, but also induces a larger deflation due to the ensuing readjustment of pressure within the magmatic column. It is thus reasonable to envision that the pressure in the conduit, $P_{i}$, lies between the magmastatic value and the lithostatic value. We maximize this overpressure (relative to magmastatic) source by assuming that the walls are able to fully reestablish a lithostatic gradient in the conduit (e.g., Mitchell, 2005):

$$
\Delta P_{i}=\rho_{w} g z-P_{i-1}-\rho_{i} g \Delta z_{i}
$$

where $z=\sum \Delta z_{i}$ and $\rho_{w}$ is the wallrock density $\left(2600 \mathrm{~kg} / \mathrm{m}^{3}\right)$. In this view, wallrock elasticity fully accommodates the pressure difference between magma and wallrock, possibly yielding conduit constriction or swelling.

\subsection{Mechanism 3: Overpressure generated by microlite crystallization}

Decompression-induced microlite crystallization generates overpressure if the magma column is rapidly emplaced and crystallizes as a closed system (e.g., Stix et al., 1997; Sparks, 1997). This situation has been modeled by Tait et al. (1989) taking into account the contributions of water exsolution, wallrock and melt elasticity, initial exsolved gas, and crystal contraction:

$$
f\left[1+\frac{\rho_{g}}{w_{i}}\left(\frac{1}{\rho_{c}}-\frac{1}{\rho_{m}}\right)\right]=1-\frac{w_{b}}{w_{i}}+\left(\frac{P_{i}}{P_{i}-\Delta P_{i}}-1\right)\left[\frac{\rho_{g}\left(P_{i}-\Delta P_{i}\right)}{\rho_{m} w_{i}}\left(\frac{1}{\mu}+\frac{1}{\beta}\right)+\frac{x_{i}}{w_{i}}\right]
$$

where $f$ is the volume fraction of microlites formed, $\rho_{g}$ is the gas density at $P_{i}, w_{i}$ is the melt water content after crystallization at $P_{i}, w_{b}$ is the melt water content before crystallization at $P_{i}-\Delta P_{i}, \mu$ is the wallrock rigidity $\left(10^{10} \mathrm{~Pa}\right.$ when wallrock is rigid and intact, and $3 \times 10^{7} \mathrm{~Pa}$ 
when wallrock is soft, Widiwijayanti et al., 2005), and $\beta$ is the melt bulk modulus $\left(10^{10} \mathrm{~Pa}\right.$, Tait et al., 1989). Burgisser et al. (2010) showed that Soufrière Hills magma obeys the solubility law proposed by Liu et al. (2005). For simplicity, we fitted the Liu et al. (2005) polynomial law to the simpler form used by Tait el al. (1989), $w_{i, b}=k P_{i, b}^{n}$ with $k=3.24 \times 10^{-3}$ and $n=0.5273$. Calculations done with the full polynomial law yield $\leq 5 \%$ difference on $z$ at very shallow depth $(<8 \mathrm{~m})$, decreasing rapidly to $<1 \%$ difference at greater depth. We used the bulk microlite content in Table 1, and we calculated $\Delta P_{i}$ by iteration from Equ. (4).

At the core of this pressurization mechanism is water exsolution into existing bubbles, which causes pressure to increase. This increase is counteracted by the elasticity of the wallrock and the melt, by the contraction due to crystallization, and by contraction of existing bubbles, which all make additional space available. The respective pressure reduction of these three mechanisms is $1-30 \%, 0-4 \%$, and $1-35 \%$, respectively, the lowest values corresponding to shallow depths.

\subsection{Mechanism 4: Overpressure generated by magma flowage}

Magma ascent can generate overpressure by the combined effects of mass conservation and increasing viscosity as degassing proceeds (e.g., Sparks, 1997; Voight et al., 1999; Wylie et al., 1999; Diller et al., 2006; Clarke et al., 2007; Costa et al., 2007; Hale and Mühlhaus, 2007). We simulated such flow-induced overpressure by parameterizing model outputs from four studies. In the first study (Melnik and Sparks, 2002), we used a run without crystallization in the conduit and a standard permeability law (i.e. similar to that of Klug and Cashman, 1996), which corresponds to taking case (i) with $\mathrm{k}_{0}=1$ in Fig. 5 of Melnik and Sparks (2002). To combine their outputs of porosity, $\alpha(z)$, and overpressure with respect to lithostatic, $\Delta P_{l}(\mathrm{z})$, we first fitted their model outputs with two log-logistic laws (e.g., Varley et 
al., 2006): $\Delta P_{l}(z)=\varepsilon_{P} \delta_{P} \gamma_{P} z^{\gamma_{P}-1}\left[1+\delta_{P} z^{\gamma_{P}}\right]^{-2}$ and $\alpha(z)=\varepsilon_{\alpha} \delta_{\alpha} \gamma_{\alpha} z^{\gamma_{\alpha}-1}\left[1+\delta_{\alpha} z^{\gamma_{\alpha}}\right]^{-2}$. Beyond the excellent degree of fit they provide, these empirical laws can also easily be integrated. The values of the parameters $\varepsilon, \delta$, and $\gamma$ are simply obtained by a least-squares regression of the respective model outputs. The overpressure with respect to the magma column, $\Delta P_{i}$, can then be retrieved by using:

$$
\Delta P_{l}(z)+\rho_{w} g z=\Delta P_{i}+\int_{0}^{z} \rho_{b}(z) g d z
$$

where $\rho_{b}(z)$ is the magma bulk density as a function of depth, the integral is the pressure due to the weight of the magmatic column alone and, following Melnik and Sparks (2002), $\rho_{w}=\rho_{m}=2600 \mathrm{~kg} / \mathrm{m}^{3}$. Using Equ. (2) with $\rho_{g}=0$ to express the magma bulk density and using the log-logistic laws to express porosity and overpressure as a function of depth, Equ. (5) becomes:

$$
\Delta P_{i}=\varepsilon_{P} \delta_{P} \gamma_{P} z^{\gamma_{P}-1}\left[1+\delta_{P} z^{\gamma_{P}}\right]^{-2}+\rho_{m} g \varepsilon_{\alpha}\left(1-\frac{1}{1+\delta_{\alpha} z^{\gamma_{\alpha}}}\right)
$$

The second study was that of Hale and Mühlhaus (2007). The overpressure with respect to magmastatic was directly given in their Fig. 6A, so we simply fitted to their model outputs the following law: $\Delta P_{i}(z)=\varepsilon_{i} \delta_{i} \gamma_{i} z^{\gamma_{i}-1}\left[1+\delta_{i} z^{\gamma_{i}}\right]^{-2}$. The third study was that of Hautmann et al. (2009), which is based on the conduit flow model of Costa et al. (2007). Here also, the overpressure in their Fig. 2 is given with respect to magmastatic, and the same law was used to fit $\Delta P_{i}(z)$ to their profile. Finally, the study by Clarke et al. (2007) presented only a porosity profile in their Fig. 6A, which we parameterized in a similar fashion to that of Melnik and Sparks (2002). As it was insufficient to calculate an overpressure profile, we only use the study of Clarke et al. (2007) to compare model-generated porosities with our dataset. Table 2 gives values of the parameters $\varepsilon, \delta$, and $\gamma$ for each of the four conduit models. 


\subsection{Effect of sudden overpressure release at explosion initiation}

Syn-explosive degassing is responsible for a significant fraction of the vesicularity measured in the ejecta (Giachetti et al., 2010). There is also textural evidence that some magma expansion occurred between explosion onset and fragmentation (Giachetti et al. 2010; Burgisser et al., 2010). Assuming that explosion triggering is caused by the sudden release of the overpressure, our data allows us to picture the reaction of the average magmatic column to the brutal return to the background pressure. We assume full overpressure loss, which maximizes pre-fragmentation column expansion. Each slice gets to a new pressure $P_{\text {i new }}$ :

$$
P_{\text {inew }}=\max \left(P_{a t m}, P_{i}-\Delta P_{i}\right)
$$

Considering that the conduit does not vary in diameter during the brutal overpressure loss, the inflation or deflation of each slice obeys:

$$
\Delta z_{i} \rho_{i}=\Delta z_{\text {inew }} \rho_{\text {inew }}
$$

The new magma bulk density, $\rho_{\text {i new, }}$ is calculated by Equ. (2) at the new pressure and vesicularity, $\alpha_{i \text { new }}$, which is related to the mass fraction of exsolved gas the slice contains, $x$, by:

$$
\frac{1}{\alpha_{\text {inew }}}=1+\frac{(1-x) \rho_{g}}{x \rho_{m}}
$$

If no syn-explosive degassing occurs, $x=x_{i}$ is the pre-explosive exsolved water content given in Table 1. If syn-explosive degassing occurs, $x=x_{i \text { new }}$ is the new exsolved content after pressure readjustment. We used the Liu et al. (2005) solubility model at $850^{\circ} \mathrm{C}$ and zero $\mathrm{CO}_{2}$ pressure to obtain the water dissolved in the melt, $m_{i}$ and $m_{i \text { new }}$, at $P_{i}$ and $P_{i \text { new }}$, respectively. Taking into account that the exsolved $\mathrm{H}_{2} \mathrm{O}, x$, is evaluated with respect to the melt and bubble mixture, whereas the dissolved $\mathrm{H}_{2} \mathrm{O}, m$, is evaluated with respect to bubble-free melt, a simple mass balance yields: 


$$
x_{\text {inew }}=x_{i}+\frac{\left(1-x_{i}\right)\left(m_{i}-m_{\text {inew }}\right)}{\left(1-m_{\text {inew }}\right)}
$$

\section{Results}

\subsection{Overpressures created by each mechanism}

Periodic inflation/deflation cycles of 6 to 14 hours occurred in the months before the 1997 Vulcanian explosions (Voight et al., 1998). Each inflation was ended by a dome collapse event of variable size. Inverse modeling of tilt data suggests that these cycles were caused by a periodic overpressure source of 1 to $4 \mathrm{MPa}$ localized between 740 and $970 \mathrm{~m}$, regardless of dome size (Widiwijayanti et al., 2005). Before all tiltmeters were destroyed by the Vulcanian explosions, data collected during the two first explosions show the same pattern: each inflation ended by an explosion. This shows that the periodic source was still active during the Vulcanian events. The tilt pattern changed little between the two types of events, whether partial dome collapse or Vulcanian explosion (Voight et al., 1999). This indicates that this source alone cannot fully account for the overpressure at the origin of the explosions, and that some decoupling must be considered. Recent studies revisiting the origin of the periodic overpressures agree with such a view (Lane et al., 2008; Lensky et al., 2008; Hautmann et al., 2009). In this section, we simply consider whether each of the four mechanisms is able to generate by itself an overpressure compatible with the periodic source. The next section is devoted to mechanism coupling.

The periodic source occurs relative to a background state that is generally considered as a lithostatic gradient everywhere but near and within the conduit (e.g., Voight et al., 1999; Widiwijayanti et al., 2005). The background state of the conduit and its vicinity, however, is largely unknown and is sensitive to the pressure distribution within the magmatic column 
(Widiwijayanti et al., 2005), suggesting that the conduit walls are not fully rigid. As endmembers, we consider that the pressure background is near-magmastatic where walls are rigid and near-lithostatic where walls yield. We first present the effects of each of the four mechanisms when the overpressure is measured with respect to magmastatic.

Our simplified treatment of gas-induced overpressure (Mechanism 1) assumes that gas accumulates below a plug without affecting magma porosity. The overpressure we impose on the magma column is thus adding to the magmastatic background level without changing the thickness of each slice of the column. Two extreme overpressure distributions can be drawn based on 1) the likely depth of the plug (from the base of the dense zone to that of the heterogeneous zone), 2) the tensile strength of each slice and 3) the depth and magnitude of the periodic source. This is illustrated in Fig. 2 and, for comparison with the other mechanisms, in Fig. 3. The plug is constrained to lie between 40 and $600 \mathrm{~m}$ deep, and the value of gas overpressure varies from 8 to $20 \mathrm{MPa}$, the higher value corresponding to the shallowest plug. The triangle-shaped overpressure brings the total plug pressure to $21 \mathrm{MPa}$ for the shallowest plug and $17 \mathrm{MPa}$ for the deepest plug, creating a region of gas accumulation from 600 to $1100 \mathrm{~m}$ thick.

Wall-induced overpressure (Mechanism 2) yields a smooth, steep gradient starting at low values and reaching $15 \mathrm{MPa}$ at depth (Fig. 3). The error attached to that curve corresponds to the cumulative effect of uncertainties on $\alpha_{i}$ and $P_{i}$. The magnitude of the magmastatic overpressure at $\sim 800 \mathrm{~m}$ is about $5 \mathrm{MPa}$, which is comparable to that of the periodic source.

Overall, microlite-induced overpressure (Mechanism 3) increases with depth (Fig. 3). This trend is overprinted by oscillations that increase in magnitude (up to $\sim 13 \mathrm{MPa}$ ) with depth. The error attached to that curve corresponds to the uncertainty on measured microlite volume fraction $f( \pm 10 \%)$. Uncertainties on $\alpha_{i}$ and $P_{i}$ yield errors of similar magnitude. To a 
first order, we note that the microlite contents of the samples are such that the lithostatic gradient is roughly re-established (i.e. almost equal to the wall-induced values).

Flow-induced overpressures (Mechanism 4) from three of the conduit flow models yield a sharp gradient at shallow depth that flattens below $1 \mathrm{~km}$ (Fig. 3). The two first models (Melnik and Sparks, 2002; Hale and Mühlhaus, 2007) reach a nearly constant value of $~ 13-15$ MPa above magmastatic, whereas the third model (Hautmann et al., 2009) reaches $32 \mathrm{MPa}$ at $2500 \mathrm{~m}$ depth. This wide variation of overpressures is related to the set of assumption made in each model. The two first models both assume a cylindrical conduit, and treat the magma as either a Newtonian, bubbly fluid (Melnik and Sparks, 2002) or as a viscoplastic, bubble-free material (Hale and Mühlhaus, 2007). This rheological difference is the main reason for the distinct overpressure profiles of these two models. Hautmann et al. (2009) also consider a Newtonian, bubbly magma, but simulate a more complex conduit geometry: a cylinder from vent to $\sim 1.2 \mathrm{~km}$ depth that is smoothly followed by a $\sim 450-\mathrm{m}$-wide, $\sim 2-\mathrm{m}$ thick dyke below. This geometrical change is the main reason for the much larger overpressures they predict.

The model of Melnik and Sparks (2002) assumes fully rigid walls and was not designed to fit the periodic pressurization of a region of Soufrière Hills' conduit. The model used by Hautmann et al. (2009), however, updates that of Melnik and Sparks (2002) by considering the dynamic behavior of the magma-wall interface. Both this model and that of Hale and Mühlhaus (2007) consider that the background stress state is given by the pressure distribution within the conduit at the minimum of each deformation cycle, which is generally between magma- and lithostatic (Denlinger and Hoblitt, 1999; Neuberg et al., 2006; Green et al., 2006; Lensky et al., 2008). In this view, overpressure is generated by shear stress at conduit wall, and the geodetic measurements at Soufrière Hills must be reinterpreted by means of an anisotropic pressure source located between $<1000 \mathrm{~m}$ and $\sim 260 \mathrm{~m}$, and consisting of only $0.5-1.5 \mathrm{MPa}$ of shear stress that the magma applies to the conduit wall (Green et al., 
2006). Thus, both Hautmann et al. (2009) and Hale and Mühlhaus (2007) consider semi-rigid walls and their model outputs are in implicit agreement with the observed edifice deformation.

\subsection{Mechanism coupling}

We can briefly revisit the overpressures profiles considering a coupling between wall elasticity (Mechanism 2) and the three other mechanisms. If walls yield fully to the pressure difference between the magmastatic and the lithostatic level, they would also fully accommodate the overpressure caused by the three other mechanisms and re-establish a lithostatic gradient. Mechanism 3 allows us to illustrate this process because Equ (4) explicitly takes in account wall rock elasticity. Setting wallrock bulk modulus to the lowest acceptable value $\left(3 \times 10^{7} \mathrm{~Pa}\right.$, Widiwijayanti et al., 2005) causes a quasi flat overpressure profile than is mostly below $1 \mathrm{MPa}$ (Fig. 4). Full overpressure accommodation occurs if the wallrock bulk modulus, $\mu$, is such that the pressure, $\Delta P$, and the density, $\Delta \rho$, differences between magma and wallrock are compensated:

$$
\mu=\frac{\Delta \rho}{\rho_{w} \Delta P}
$$

Figure 5 indicates that very soft walls could reestablish a lithostatic gradient, regardless of the mechanism. Complete canceling of overpressure is incompatible with the occurrence of Vulcanian explosions, which suggests this end-member scenario is unlikely. Considering conduit walls as semi-rigid seems the most realistic scenario. In our simple approach, this would correspond to a moderated version of Mechanism 2 or to the two most recent models embedded in our evaluation of Mechanism 4.

\subsection{Pre-explosive density distribution}


Figure 6 shows five columns indicating possible density distributions of the magma just prior to a Vulcanian explosion. Following Burgisser et al. (2010), we selected the shallowest group of dense samples to define the dense cap (I) of the magmatic column, the following heterogeneous and breadcrusted samples to define the transition zone (II), and the deeper homogeneous pumices to define the homogeneous zone (III). The boundaries of these zones are somewhat arbitrary, but consistently vary in relative thickness as a function of overpressure mechanism. The first column in Fig. 6 corresponds to gas-induced overpressure (Mechanism 1) and represents the magmastatic case with no overpressure. The two next columns correspond to wall-induced overpressure (Mechanism 2) and microlite-induced overpressure (Mechanism 3), respectively. Flow-related columns differ depending on the conduit flow model considered (Mechanism 4). The fourth column corresponds to the models of Melnik and Sparks (2002) and Hale and Mühlhaus (2007), and the last column corresponds to the Hautmann et al. (2009) model. The base of the transition zone occurs the deepest, 721 $\mathrm{m}$, with gas overpressure. The other mechanisms bring this limit upwards, $461 \mathrm{~m}$ for wall-, $539 \mathrm{~m}$ for microlite-, and 50-191 $\mathrm{m}$ for flow-induced overpressures, respectively. We note that the cap generated by flow-induced overpressure is so thin that it is dangerously close to the upper boundary of the system (0.02-0.2 $\mathrm{m}$ vs. 30-50 $\mathrm{m}$ for the other scenarios). The total column height varies less; it lies between 3.2 and $4.2 \mathrm{~km}$ for all columns except the last one. This much shorter $(\sim 2.5 \mathrm{~km})$ magmatic column is due to the large overpressures produced by the Hautmann et al. (2009) model.

\subsection{Overpressure release and column expansion at explosion initiation}


To avoid the multiplication of scenarios, we leave Mechanisms 2 and 3 aside because their overpressures are framed by the two other mechanisms. If, on one hand, explosion triggering is caused by the sudden rupture of an impermeable plug, as in Mechanism 1, the overpressure caused by gas accumulation is released. We imposed that this overpressure was large enough to explain plug rupture (Fig. 2). If, on the other hand, explosion triggering is caused by the sudden release of flow-induced overpressure (Mechanism 4), the release will be related to viscous plug rupture. Plug rupture rapidly eases flowage and reduces the dynamic pressure in the shallow part of the conduit by replacing the strong viscous resistance of the plug by the much lower friction of its ruptured pieces. In all cases, the pressure returns to magmastatic level. We evaluate the role of syn-explosive degassing (i.e. water exsolution occurring during explosion, which comprises vesiculation of new bubbles and growth existing ones) on column expansion for each mechanism.

Figure 7 shows two bounds of column expansion for three scenarios: gas accumulation in deep and shallow plugs (Mechanism 1), and flow-induced overpressure (Mechanism 4). For each scenario, the upper bound, or maximum expansion, is obtained when syn-explosive degassing is allowed to occur, whereas the lower bound, or minimum expansion, is obtained when no syn-explosive degassing occurs. As expected, the magnitude of the overpressure is a main control of the amount of expansion, which is maximized by the large overpressures produced by shallow plugs or magma flow. The role of syn-explosive degassing is more complex. In Mechanism 1, syn-explosive degassing multiplies expansion by a factor of $\sim 100$, regardless of plug depth. The resulting expansion of the few hundred meters below the freshly ruptured plug remains modest (10\%) for a deep plug and consequent $(100 \%)$ for a shallow plug. The influence of syn-explosive degassing is subdued in Mechanism 4, where it multiplies expansion by a factor of $\sim 4$, regardless of depth. As a result, the whole column of Mechanism 4 is likely to feel a strong expansion, from a few percent at depth to $50-100 \%$ at 
shallow levels $(<1 \mathrm{~km})$. The high expansion values at shallow depth $(<200 \mathrm{~m}$, Fig. 7) are unrealistic because the column expands upwards, rapidly over-topping the vent. We can nevertheless state that the top part of the column is most subject to high strains when expanding as a whole because expansion is cumulated from the base of the column upwards. Overall, large overpressures at shallow level, such as those produced by magma flowage or shallow plugs, and efficient syn-explosive degassing are most enhancing pre-fragmentation column expansion.

\section{Discussion}

The reasoning we used herein has limitations. First, the data we used are themselves the results of interpretation. This is clear for the conduit flow model outputs and for the geodetic data, which are thought to be caused by either a damaged, localized part of the conduit, or shear stresses along conduit walls. Requesting the most perfect fit between all the constraints, as presented in the Result section, assumes that no other mechanisms than the four formalized herein were at play during the Vulcanian explosions. The sudden release of any of these overpressures, however, is likely to involve other processes (e.g., plug rupture) that are not included into the four mechanisms we address herein. In other words, there are additional triggering processes that cannot be explored using our data. We believe that the value of our approach lies in the systematic quantification of the pressurization mechanisms that are known well enough to be formalized by first-order relationships.

\subsection{Assessment of each overpressure mechanism separately}


Gas-induced overpressure (Mechanism 1) is an end-member scenario that considers gas transfer without porosity change (Fig. 3). We can use this end-member to estimate what would happen if gas transfer causes porosity to vary, although the full modeling of such process is beyond the scope of this work. If the accumulated gas is allowed to dissolve back into the magma, it would raise pre-explosive melt water content by $1.29 \mathrm{wt} \%$ for a shallow plug and by $0.38 \mathrm{wt} \%$ for a deep plug. These values are above the analytical errors on melt water content for samples lying within the relevant depths (the median error is $0.02 \mathrm{wt} \%$ ). A systematic sampling should feature a large number of samples with a melt water content corresponding to the plug pressure (inset, Fig. 2). Unfortunately, the sampling done by Burgisser et al. (2010) aimed at maximizing the textural variations and cannot be used to statistically locate a preferential plug pressure. The large overpressures occurring above the periodic source and below the plug level should cause edifice deformation. Invoking the fact that deformation might be too shallow to be registered by tiltmeters, however, seems excessively complicated. Instead, we favor deep plugs that concentrate the overpressure in the vicinity of the periodic source. Sealing and pressure buildup must have been much faster than column emplacement, because the magmatic column was emplaced under open system degassing (Burgisser et al., 2010). Under these conditions, Mechanism 1 alone could cause overpressures compatible with periodic deformation and explosion trigger.

Mechanism 2 assumes a conduit fully bounded by soft walls, which causes the maximum overpressure to occur the deepest (Fig. 3). The magnitude of the magmastatic overpressure is comparable to that of the periodic source. This scenario can thus be consistent with geodetic measurements if walls are soft at that specific level and rigid elsewhere, as fully rigid walls rule out any overpressure by this mechanism. Fast upward movement of such a pressure-balanced magmatic column would cause inflation of the soft level by bringing deeper, more pressurized magma at that level. This is consistent with the fact that a conduit 
fully bounded by soft walls would be able to absorb other sources of overpressure (Fig. 5). Thus, a conduit mostly bounded by rigid walls except for a small region where walls are soft can be reconciliated with a periodic deformation. Mechanism 2, however, is less likely to be also the cause of explosion triggering because it is hard to imagine that conduit walls can suddenly rigidify and brutally cancel the overpressure.

The overpressure distributions created by the rapid filling of the conduit followed by closed system crystallization (Mechanism 3) are difficult to conciliate with geodetic measurements, even by assuming a convenient sequence of rigid and soft conduit walls (Fig. 3). Crystallization-induced overpressures, which are based on closed-system degassing, are overestimates because extensive gas leakage occurred at various depths. This is supported by the presence of numerous deformed and coalesced pre-explosion bubbles (Formenti and Druitt, 2003; Giachetti et al., 2010), and the far-from-equilibrium porosities we infer in the pre-explosive magmatic column (Burgisser et al., 2010). The requirement that the magma column was sealed long enough to allow crystallization and pressure buildup is in contradiction with these other evidence of open system degassing. It is thus unlikely that Mechanism 3 contributed significantly to the periodic source or explosion trigger. We conclude that microlite crystallization plays a subordinate role in overpressure genesis at Soufrière Hills.

Let us focus our attention on the $0.2-\mathrm{m}$ plug predicted by Mechanism 4. Onedimensional flow models are by essence not aimed at simulating the complexities of dome growth (Massol et al., 2001; Watts et al., 2002; Hale and Wadge, 2008). The close proximity of the plug to the vent drives us to simply consider that a flow-induced plug would be much thinner than that inferred from the other mechanisms. The viscosity increase caused by melt water loss induces large dynamic pressures at shallow depth. These pressures have to vanish at the vent, thus all samples that recorded small pre-explosive pressures had to be located at 
very shallow level. Since these samples are mostly dense, they represent a thin, very shallow cap.

The models underlying our assessment of Mechanism 4 involve a large number of processes. By converting model-generated lithostatic overpressures to magmastatic overpressures (Equ. (6)), we implicitly assumed that the calculated evolution of porosity was similar to that of our data because model outputs are depth-referenced. To test this assumption, we compare our baseline data on pre-explosive pressures and porosities (Table 1) with the outputs from the flow model of Clarke et al. (2007). Figure 8 shows a remarkable agreement between model outputs and our dataset. This favorable outcome can easily be extended to our analysis of the overpressures predicted by these models and the resulting pressure-to-depth conversions because the model of Clarke et al. (2007) is based on that of Melnik and Sparks (2002) and thus share most of their physics.

Can our pressure-to-depth conversions be improved by fine-tuning the conduit flow models? The Melnik and Sparks (2002) model run upon which our overpressure distribution is based features the "standard" permeability law. Changing this law varies the magnitude of the overpressure and the porosity maximum but not their depth distribution. The other controls on these two parameters are 1) mass flux, which, upon increasing, causes both overpressure and porosity maximum to shallow and grow (Diller and al., 2006), and 2) conduit geometry, the narrowing of which mostly affects the pressure profile (de' Michieli Vitturi et al., 2008). It should be kept in mind that even calibrated model runs that better match our pre-explosive porosity distribution will yield overpressures that span a much larger range of depths than those inferred for the periodic source by Widiwijayanti et al. (2005). Hale and Mühlhaus (2007) and Hautmann et al. (2009), on the other hand, suggested that conduit flow model must include magma-wall interaction to be in agreement with the periodic source. Steady-state flowage tends to force softer walls in an upward convergent 
configuration because flow-induced decompression is stronger at shallow depth (Giberti and Wilson, 1980; Mastin, 2002; Mitchell, 2005). More rigid walls, on the other hand, cause greater flow ascent velocities by allowing stronger decompressions (Giberti and Wilson, 1990). Wall elasticity may also introduce short-period unsteadiness in mass flux with associated pressure variations within the magmatic column (Costa et al., 2007). Conduit geometry and the appearance of conduit constrictions greatly impact overpressure distribution (Fig. 3; de' Michieli Vitturi et al., 2008). Despite the fact that, to first order, Mechanism 4 is compatible with the periodic source and the generation of overpressures able to trigger the Vulcanian explosions, these complex interactions demonstrate that it is difficult to isolate the effects of Mechanism 4 from those of Mechanism 2. Fine-tuning thus seems to involve an unavoidable integration of magma-wall interaction into conduit flow models.

\subsection{Coupling the overpressure mechanisms}

We have seen that, in general, rigid walls favor large overpressures by the other mechanisms and soft walls dampen these variations. Magma-wall interaction (coupling of Mechanisms 2 and 4) is able to explain the periodic source without other pressurization mechanisms. This is suggested by 1) the likely influence of magma flow on the conduit walls (e.g., Hale and Mühlhaus, 2007) and 2) the good fit between our data and flow model outputs (Fig. 8). Pressure buildup leading to explosion trigger, on the other hand, is most compatible with gas accumulation below a plug and magma flowage (Mechanisms 1 and 4) because these two mechanisms are the only ones able to produce overpressures large enough to cause plug rupture. There is no reason, however, to assume a systematic coupling between Mechanisms 1 and 2 because it is likely that the periodic source was mostly decoupled from the overpressure triggering the Vulcanian explosions. In other words, gas accumulation could have occurred in 
a rigid part of the conduit without transmitting the associated pressurization to the whole edifice if concurrent magma flowage through a semi-rigid conduit occurred below. We thus can relax our previous conclusion that gas accumulation requires deep plugs to concentrate the associated increase in pressure in the vicinity of the periodic source. Instead, shallow plugs create the most effective pressurization in the more rigid part of the conduit located above the periodic source.

In summary, magma flowage is sufficient to cause periodic edifice deformation through semi-rigid conduit walls and build overpressures able to trigger explosions. Gas accumulation below a shallow plug is also able to build such overpressures and can occur regardless of magma flowage. The concurrence of these three mechanisms offers the highest likelihood of building overpressures leading to the 1997 explosion series.

How does the 1997 series at Montserrat compare with other Vulcanian explosions? Table 3 summarizes the pressurization mechanisms thought to occur at 6 other volcanoes displaying such eruptive behavior. Eruptive sequences can be divided in two cases, whether the magmatic column is essentially static when the explosions occur (Galeras, Lascar, Ngauruhoe, and Sakurajima), or flowing, such as when explosions occur during dome extrusion (Arenal, Colima, and Montserrat). In static columns, sealing has the time to happen by hydrothermal activity. Pressurization by crystallization has carefully been evaluated at Galeras (Stix et al., 1997), and seems consistent with an essentially static, sealed column. At Montserrat, on the other hand, flowage under open system degassing and the short time spend with a plug played against pressure buildup by crystallization. Under this light, the crystallization proposed at Colima (e.g., Varley et al., 2010a) might not be directly related to the Vulcanian explosions because conditions (flowage and many shortly spaced explosions) are adverse to significant pressure buildup. Flowing columns, on the other hand, are mostly blocked by wallrock debris or stiffening of the new magma. A peculiar sealing by temporary 
blockage of the explosive vent by degassed lava flowing from another vent has been proposed at Arenal (Williams-Jones et al., 2001). This could not happen in dome-forming eruption, and is possible at Arenal because of the low-viscosity lava involved, which causes the explosive activity to be mostly (violent) Strombolian with few Vulcanian events (Soto and Alvarado, 2006).

Could the relatively young age of Soufrière Hills' conduit (2 years in 1997) favor elastic response of the conduit wall and stress transmission from the edifice to the magma column? Although cyclic stressing of rock causes a decrease of elastic modulus (e.g., Heap et al., 2010), there are two lines of evidence that it is not likely. Arenal is the only other case where the stress state of the edifice is thought to cause pressure changes of the magma column. The conduit at Arenal, however, is well established with 32 years of continuing activity. Another well-established conduit is that of Sakurajima, where pressure buildup is caused by gas accumulation with few interactions with the well-sealed conduit (e.g., Iguchi et al., 2008).

Being part of the Vulcanian behavior paradigm, gas accumulation is systematically invoked but, except at Sakurajima and possibly at Ngauruhoe, it is always accompanied by at least another mechanism. Like sealing, there seems to be a combination of causes to build up pressure in a magmatic column. The fact that some volcanoes, such as Lascar or Ngauruhoe, have few explosions years apart, whereas others produce numerous series, such as Montserrat or Sakurajima, does not seem linked to a particular combination. The eruptive sequences are the result of very complex feedback mechanisms and there is therefore not a single explanation applicable to all of them, despite their similarities. This is reinforced by the fact that the studies to which we refer involve different degrees of detail, so that not all mechanisms have been evaluated at every volcano. 


\subsection{Processes at play at explosion initiation}

The classic vision of a Vulcanian explosion is that a sudden loss of overpressure causes a fast pressure wave followed by a fragmentation front that causes brittle breakup an essentially still magma column (Fig. 9, left; e.g., Kennedy et al., 2005). If magma expansion is allowed to occur, another case becomes possible because expansion causes uprise of foamed up magma towards fragmentation. It is well known that degassing can cause magma column expansion, and Figure 7 suggests that the modest syn-explosive degassing occurring at Soufrière Hills could have played a significant role in helping the column to expand. To illustrate such a scenario, it is easiest to picture an end-member situation: the fragmentation front being quasi-still and fed by a rapidly expanding column (Fig. 9, right). It should be kept in mind that, since the magma column can only expand upwards, the expansion speed of the shallow part is going to be a cumulated speed from all the other parts below. Whether significant expansion speed can be achieved during the 10-20 s time span of the explosions despite the resistance opposed by wall friction (Lensky et al. 2008) is a complex problem involving bubble-scale dynamics to conduit-scale flow of the magma. The insets in Fig. 9 give a stepwise illustration of the column expansion for Mechanisms 1 and 4 if its lowermost part is considered fixed and the new, expanded thickness of each slice is cumulated upwards. We left out of our analysis the first few hundred meters of the column that are so evacuated. Starting from the over-pressurized profile in black, the column goes back to magmastatic level in successive lighter shades of gray representing expansion without gas exsolution, $50 \%$ syn-eruptive vesiculation, and 100\% vesiculation, respectively. Release of gas-accumulated overpressure causes little expansion, and fits well with the classical view. The sudden release of flow-induced overpressure, on the other hand, is sufficient to force the extrusion of several hundreds of meters of the column by expansion. The absence of independent timing other 
than explosion duration, however, does not allow us to explore whether such strains may have generated fragmentation, as suggested by Lane et al. (2008). This is an interesting possibility, as it would make expansion the main engine that propagates the fragmentation front.

Column expansion due to volatile degassing has been shown to play an important role after conduit evacuation (Nishimura, 2009). Considering the role of such an expansion during conduit evacuation, however, brings another intriguing idea: the conduit could be mostly full of partially expanded magma after the explosion. We have seen that conduit geometry controls ascent rates and magma overpressures, which suggests that the conduit remained open long enough between explosions to be refilled without major collapse. Collapse time scale being conditioned by the rigidity of the conduit (Quareni and Mulargia, 1993), it implies that the conduit was never emptied below the level of the periodic source. Figure 6, however, shows that evacuation was much deeper than that source. Having the conduit partly filled with foamy magma between explosions is thus an attractive alternative to explain source preservation.

We expect that the interplay between fragmentation front and column expansion is much more complex than the simple dual view pictured in Fig. 9. Strainmeter data showing measurable conduit reaction during more recent Vulcanian explosions illustrate such a complexity. Conduit reaction in 2003 (Voight et al., 2010), 2008, and 2009 (Chardot et al., 2010) was a rapid contraction suggesting magma evacuation over a depth inferior to $\sim 2 \mathrm{~km}$. Conduit reaction during the March 2004 explosion (Linde et al., 2004), however, was probably deeper $(>\sim 1.5 \mathrm{~km})$ and is difficult to link to conduit evacuation. Just after overpressure release, magma evacuation causes a fragmentation-induced unloading that furthers the decompression felt by each slice. This is expected to increase column expansion, but front propagation might be so fast that further expansion would occur post-fragmentation. This situation has been modeled in far greater details by Mason et al. (2006), albeit 
considering no syn-explosive bubble nucleation. Finally, walls being most likely semi-rigid, plug rupture does not simply suppress flow-induced overpressure, but also causes complex wall response (Iguchi et al., 2007). Our assumption that the conduit diameter does not vary during explosion (Equ. (8)) limits further exploration of this phenomenon.

\section{Conclusions}

We used the pre-explosive pressures and porosities for the 1997 Vulcanian explosions at Soufrière Hills determined by Burgisser et al. (2010) to build a depth-referenced density profile of the magmatic column. The conversion from pressure to depth was carried out by balancing the magma load within the conduit and taking into account the effect of an independently imposed overpressure. We tested the four mechanisms of pressure buildup thought to occur at Montserrat: 1) gas accumulation, 2) conduit wall elasticity, 3) microlite crystallization, and 4) magma flowage. The three first mechanisms yield magmatic columns of similar sizes, and the fourth yields a shorter column. The three-part vertical layering of the conduit prior to explosion is proposed to have been spatially distributed as: 1) a dense and strongly degassed plug a few tens of meters in thickness, 2) a shallow transition zone characterized by complex mingling between vesicular and dense magma with thickness varying from 400 to $700 \mathrm{~m}$, depending on the overpressure mechanism, and 3) at greater depth, a more homogeneous, low-porosity zone that brings the total column length to $\sim 3.5$ km. Flow-induced overpressure yields a dense cap of less than a few meters thick, a heterogeneous zone from 200 to $500 \mathrm{~m}$ thick, and a total column length as low as $2.5 \mathrm{~km}$.

Inflation/deflation cycles linked to a periodic overpressure source offer a unique dataset that we attempt to use to constrain the four overpressure mechanisms. Overall, magma flowage is sufficient to cause periodic edifice deformation through semi-rigid conduit walls 
and build overpressures able to trigger explosions (coupling of Mechanism 2 and 4). Pressure buildup leading to explosion trigger, on the other hand, is most compatible with gas accumulation below a plug and magma flowage (Mechanisms 1 and 4) because these two mechanisms are the only ones able to produce overpressures large enough to cause plug rupture. Pressure buildup could thus have been caused by either Mechanism 1 or a coupling between Mechanisms 2 and 4. Since periodic deformation occurred prior to and during the Vulcanian explosions, the most likely scenario involves flow-induced overpressure with the appearance of an impermeable plug that causes additional pressure buildup. Our data are compatible with the explosions resulting from the sudden release of these coupled overpressures. We realize that this corresponds simply to a reasonable explanation rather than the only best-fit combination possible. One might consider it as the conclusion of a systematic evaluation of the processes thought to play in Vulcanian eruptions that are known well enough to be quantified.

Finally, we explored the effects of suddenly releasing the calculated overpressures. We found that efficient syn-explosive vesiculation and large overpressures at shallow level, such as those produced by magma flowage or shallow plugs (Mechanisms 1 and 4), promote (pre-fragmentation) column expansion. The extreme expansions associated with Mechanism 4 lead us to question the classic picture of a Vulcanian explosion in which a sudden loss of overpressure causes a fragmentation front that delaminates an essentially still magma column. If magma expansion is allowed to occur, our results suggest that the motion of the fragmentation front may not be the main control of column evacuation because expansion brings foamed up magma towards fragmentation. This process can be envisioned as a quasistill fragmentation front being fed by a rapidly expanding column. 


\section{Acknowledgments}

This project was funded by the French Program ANR-EXPLANT (Contract No ANR05-CATT-003 to C. Martel) and partially funded by the ERC grant 202844 under the European FP7. We thank S. Self for a review with insightful suggestions and comments. 


\section{References}

Burgisser, A., Poussineau, S., Arbaret, L., Druitt, T.H., Giachetti, T. Bourdier, J-L., 2010. Preexplosive conduit conditions of the 1997 Vulcanian explosions at Soufrière Hills Volcano, Montserrat: I. Pressure and vesicularity distributions, J. Volcanol. Geotherm. Res. 194, 27-41.

Chardot, L., Voight, B., Foroozan, R., Sacks, S., Linde, A., Stewart, R., Hidayat, D., Clarke, A., Elsworth, D., Fournier, N., Komorowski, J.-C., Mattioli, G., Sparks, R. S. J., Widiwijayanti, C. 2010. Explosion dynamics from strainmeter and microbarometer observations, Soufrière Hills Volcano, Montserrat: 2008-2009. Geophys. Res. Lett. 37, L00E24, doi:10.1029/2010GL044661.

Clarke, A.B., Neri, A., Voight, B., Macedonio, G., Druitt, T.H., 2002. Computational modelling of the transient dynamics of the August 1997 Vulcanian explosions at Soufriere Hills Volcano, Montserrat: influence of initial conduit conditions on near-vent pyroclastic dispersal. In: Druitt, T.H., Kokelaar, B.P. (Eds.), The Eruption of Soufrière Hills Volcano, Montserrat, from 1995 to 1999. Geol. Soc., London, Memoir 21, 319-348.

Clarke, A.B., Stephens, S., Teasdale, R., Sparks, R.S.J., Diller, K., 2007. Petrologic constraints on the decompression history of magma prior to vulcanian explosions at the Soufrière Hills Volcano, Montserrat. J. Volcanol. Geotherm. Res. 161, 261-274.

Costa, A., Melnik, O., Sparks, R.S.J., 2007. Controls of conduit geometry and wallrock elasticity on lava dome eruptions, Earth Planet. Sci. Lett. 260, 137-151.

de' Michieli Vitturi, M., Clarke, A.B., Neri, A., Voight, B., 2008. Effects of conduit geometry on magma ascent dynamics in dome-forming eruptions. Earth Planet. Sci. Lett. 272, 567-578.

Denlinger, R.P., Hoblitt, R.P., 1999. Cyclic eruptive behavior of silicic volcanoes, Geology 27, 459462.

Devine, J.D., Rutherford, M.J., Norton, G.E., Young, S.R., 2003. Magma storage region processes inferred from geochemistry of Fe-Ti oxides in andesitic magma, Soufrière Hills volcano, Montserrat, W.I.. J. Petrol. 44, 1375-1400.

Diller, K., Clarke, A.B., Voight, B., Neri, A., 2006. Mechanisms of conduit plug formation: Implications for vulcanian explosions, Geophys. Res. Lett. 33, doi:10.1029/2006GL027391.

Druitt, T.H., Young, S.R., Baptie, B.J., Bonadonna, C., Calder, E.S., Clarke, A.B., Cole, P.D., Harford, C.L., Herd, R.A., Lockett, R., Ryan, G., Voight, B., 2002. Episodes of cyclic Vulcanian explosive activity with fountain collapse at Soufrière Hills Volcano, Montserrat. In: Druitt, T.H., Kokelaar, B.P. (Eds.), The Eruption of Soufrière Hills Volcano, Montserrat, from 1995 to 1999. Geol. Soc., London, Memoir 21, 281-306.

Eichelberger, J., Carrigan, C., Westrich, H., Price, R., 1986. Non-explosive silicic volcanism. Nature $323,598-602$.

Formenti, Y., Druitt, T.H., 2003. Vesicle connectivity in pyroclasts and implications for the fluidisation of fountain-collapse pyroclastic flows, Montserrat (West Indies), Earth Planet. Sci. Lett. 214, 561-574.

Formenti, Y., Druitt, T.H., Kelfoun, K., 2003. Characterisation of the 1997 Vulcanian explosions of Soufrière Hills Volcano, Montserrat, by video analysis. Bull. Volcanol. 8, 587-605.

Gardner, J.E., Thomas, R.M.E., Jaupart, C., Tait, S., 1996. Fragmentation of magma during Plinian volcanic eruptions. Bull. Volcanol. 58, 144-162.

Giachetti, T., Druitt, T.H., Burgisser, A., Arbaret, L., Galven, C. (2010) Bubble nucleation, growth and coalescence during the 1997 Vulcanian explosions of Soufrière Hills Volcano, Montserrat. J. Volcanol. Geotherm. Res., 193, 215-231. 
Giberti, G., Wilson, L., 1990. The influence of geometry on the ascent of magma in open fissures. Bull. Volcanol. 52, 515-521.

Green, D.N., Neuberg, J., Cayol, V., 2006. Shear stress along the conduit wall as a plausible source of tilt at Soufrière Hills volcano, Montserrat. Geophys. Res. Lett. 33, L10306.

Hale, A.J., Mühlhaus, H.-B., 2007. Modelling shear bands in a volcanic conduit: Implications for over-pressures and extrusion-rates. Earth Planet. Sci. Lett. 263, 74-87.

Hale, A.J., Wadge, G., 2008. The transition from endogenous to exogenous growth of lava domes with the development of shear bands. J. Volcanol. Geotherm. Res. 171, 237-257.

Hammer, J.E., Cashman, K.V., Hoblitt, R., Newman, S., 1999. Degassing and microlite crystallization during pre-climatic events of the 1991 eruption of Mt. Pinatubo, Philippines. Bull. Volcanol. 60, 355-380.

Hautmann, S., Gottsmann, J., Sparks, R.S.J., Costa, A., Melnik, O., Voight, B. 2009. Modelling ground deformation caused by oscillating overpressure in a dyke conduit at Soufrière Hills Volcano, Montserrat. Tectonophysics, 471, 87-95.

Heap, M.J., Faulkner, D.R., Meredith, P.G., Vinciguerra, S., 2010. Elastic moduli evolution and accompanying stress changes with increasing crack damage: implications for stress changes around fault zones and volcanoes during deformation. Geophys. J. Internat. 183, 225-236.

Hobden, B.J., Houghton, B.F., Nairn, I.A., 2002. Growth of a young, frequently active composite cone: Ngauruhoe volcano, New Zealand. Bull. Volcanol. 64, 392-409.

Hoblitt, R.P., Wolfe, E.W., Scott, W.E., Couchmann, M.R., Pallister, J.S., Javier, D., 1996. The preclimactic eruptions of Mount Pinatubo, June 1991. In: Newhall, C.G., Punongbayan, R.S. (Eds.), Fire and mud; eruptions and lahars of Mount Pinatubo, Philippines. University of Washington Press, 457-511.

Iguchi, M., Yakiwara, H., Tameguri, T., Hendrasto, M., Hirabayashi, J., 2008. Mechanism of explosive eruption revealed by geophysical observations at the Sakurajima, Suwanosejima and Semeru volcanoes. J. Volcanol. Geotherm. Res. 178, 1-9.

Kennedy, B., Spieler, O., Scheu, B., Kueppers, U., Taddeucci, J., Dingwell, D.B., 2005. Conduit implosion during vulcanian eruptions. Geology 33, 581-584.

Klug, C., Cashman, K.V., 1996. Permeability development in vesiculating magmas: implications for fragmentation. Bull. Volcanol. 58, 87-100.

Lane, S.J., Phillips, J.C., Ryan, G.A., 2008. Dome-building eruptions: insights from analogue experiments, In: Lane, S.J, Gilbert, J.S. (Eds) Fluid motions in volcanic conduits: a source of seismic and acoustic signals. Geol. Soc., London, Spec. Pub. 307, 207-237.

Lensky, N.G., Sparks, R.S.J., Navon, O., and Lyakhovsky, V., 2008. Cyclic activity at Soufrière Hills Volcano, Montserrat: degassing-induced pressurization and stick-slip extrusion. In: Lane, S.J, Gilbert, J.S. (Eds) Fluid motions in volcanic conduits: a source of seismic and acoustic signals. Geol. Soc., London, Spec. Pub. 307, 169-188.

Linde, A.T., Sacks, S., Hidayat, D., Voight, B., Clarke, A., Elsworth, D., Mattioli, G., Malin, P., Shalev, E., Sparks, S., Widiwijayanti C.,2010. Vulcanian explosion at Soufrière Hills Volcano, Montserrat on March 2004 as revealed by strain data. Geophys. Res. Lett. 37, L00E07, doi:10.1029/2009GL041988

Liu, Y., Zhang, Y., Behrens, H., 2005. Solubility of $\mathrm{H}_{2} \mathrm{O}$ in rhyolitic melts at low pressures and a new empirical model for mixed $\mathrm{H}_{2} \mathrm{O}-\mathrm{CO}_{2}$ solubility in rhyolitic melts. J. Volcanol. Geotherm. Res. $143,219-235$.

Mason, R.M., Starostin, A.B., Melnik, O.E., Sparks, R.S.J., 2006. From Vulcanian explosions to sustained explosive eruptions: The role of diffusive mass transfer in conduit flow dynamics. J. Volcanol. Geotherm. Res. 153, 148-165. 
Massol, H., Jaupart, C., Pepper, D.W., 2001. Ascent and decompression of viscous vesicular magma in a volcanic conduit. J. Geophys. Res. 106, 16223-16240.

Mastin, L.G., 2002. Insights into volcanic conduit flow from an open-source numerical model, Geochemistry, Geophysics, Geosystems 3, DOI:10.1029/2001GC000192.

Matthews, S.J., Gardeweg, M.C., Sparks, R.S.J., 1997. The 1984 to 1996 cyclic activity of Lascar Volcano, northern Chile: cycles of dome growth, dome subsidence, degassing and explosive eruptions. Bull. Volcanol. 59, 72-82.

Melnik, O., Sparks, R.S.J., 1999. Nonlinear dynamics of lava dome extrusion. Nature 402, 37-41.

Melnik, O., Sparks, R.S.J., 2002. Dynamics of magma ascent and lava extrusion at Soufrière Hills Volcano, Montserrat. In: Druitt, T.H., Kokelaar, B.P. (Eds.), The Eruption of Soufrière Hills Volcano, Montserrat, from 1995 to 1999. Geol. Soc., London, Memoir 21, pp.153-171.

Mitchell, K.L., 2005. Coupled conduit flow and shape in explosive volcanic eruptions. J. Volcanol. Geotherm. Res. 143, 187-203.

Morrissey, M.M., Mastin, L.G., 2000. Vulcanian eruptions. In: Sigurdson, H. (Ed.), Encyclopedia of Volcanoes. Academic Press, San Diego, 463-475.

Nairn, I.A., Self, S., 1978. Explosive eruptions and pyroclastic avalanches from Ngauruhoe in February 1975. J. Volcanol. Geotherm. Res. 3, 39-60.

Neuberg, J.W., Tuffen, H., Collier, L., Green, D., Powell, T., Dingwell, D., 2006. The trigger mechanism of low-frequency earthquakes on Montserrat. J. Volcanol. Geotherm. Res. 153, 37 50 .

Nishimura, T., 2009. Ground deformation caused by magma ascent in an open conduit. J. Volcanol. Geotherm. Res. 187, 178-192.

Quareni, F., Mulargia, F., 1993. Modeling the closure of volcanic conduits with an application to Mount Vesuvius. J. Geophys. Res. 98, 4221-4229.

Savov, I.P., Luhr, J.F., Navarro-Ochoa, C., 2008. Petrology and geochemistry of lava and ash erupted from Volcán Colima, Mexico, during 1998-2005. J. Volcanol. Geotherm. Res. 174 241-256.

Self, S., Wilson, L., Nairn, I.A., 1979. Vulcanian eruption mechanisms. Nature 277, 440-443.

Siebert L, Simkin T (2002-2010). Volcanoes of the world: an illustrated catalog of Holocene volcanoes and their eruptions. Smithsonian Institution, Global Volcanism Program Digital Information Series, GVP-3, (www.volcano.si.edu/world).

Soto, G.J., Alvarado, G.E., 2006. Eruptive history of Arenal Volcano, Costa Rica, 7 ka to present. J. Volcanol. Geotherm. Res. 157, 254-269.

Sparks, R.S.J., 1997. Causes and consequences of pressurisation in lava dome eruptions. Earth Planet. Sci. Lett. 150, 177-189.

Spieler, O., Kennedy, B., Kueppers, U., Dingwell, D.B., Scheu, B., Taddeucci, J., 2004. The fragmentation threshold of pyroclastic rocks, Earth Planet. Sci. Lett. 226, 139-148.

Stix, J., Torres, R.C., Narvaez M, L., Cortes J, G.P., Raigosa, J.A., Gomez M, D., Castonguay, R., 1997. A model of Vulcanian eruptions at Galeras Volcano, Colombia. J. Volcanol. Geotherm. Res. 77, 285-303.

Tait, S., Jaupart, C., Vergniolle, S. 1989. Pressure, gas content and eruption periodicity of a shallow, crystallizing magma chamber. Earth Planet. Sci. Lett. 92, 107-123.

Varley, N., Arámbula-Mendoza, R., Reyes-Dávila, G., Sanderson, R., Stevenson, J., 2010a. Generation of Vulcanian activity and long-period seismicity at Volcán de Colima, Mexico. J. Volcanol. Geotherm. Res. doi:10.1016/j.jvolgeores.2010.08.009. 
Varley, N., Johnson, J., Ruiz, M., Reyes, G., Martin, K. 2006. Applying statistical analysis to understanding the dynamics of volcanic explosions. In: Mader, H. M., Coles, S. G., Conno, C. B., Connor, L. J. (Eds.) Statistics in Volcanology. Spec. Publ. IAVCEI, Geol. Soc., London 1, $57-76$

Varley, N.R., Arámbula-Mendoza, R., Reyes-Dávila, G., Stevenson, J., Harwood, H., 2010b. Longperiod seismicity during magma movement at Volcán de Colima. Bull. Volcanol. doi:10.1007/s00445-010-0390-7.

Voight, B., Hoblitt, R.P., Clarke, A.B., Lockhart, A.B., Miller, A.D., Lynch, L., and McMahon, J. 1998. Remarkable cyclic ground deformation monitored in real-time on Montserrat, and its use in eruption forecasting. Geophys. Res. Lett. 18, 3405-3408.

Voight, B., Hidayat, D., Sacks, S., Linde, A., Chardot, L., Clarke, A., Elsworth, D., Foroozan, R., Malin, P., Mattioli, G., McWhorter, N., Shalev, E., Sparks, R. S. J., Widiwijayanti, C., Young, S. R. 2010. Unique strainmeter observations of Vulcanian explosions, Soufrière Hills Volcano, Montserrat, July 2003. Geophys. Res. Lett. 37, L00E18, doi:10.1029/2010GL042551.

Voight, B., Sparks, R.S.J., Miller, A.D., Stewart, R.C., Hoblitt, R.P., Clarke, A.B., Ewart, J., MVO Staff, 1999. Magma flow instability and cyclic activity at Soufriere Hills Volcano, Montserrat, British West Indies. Science 283, 1138-1142.

Watts, R.B., Herd, R.A., Sparks, R.S.J, Young, S.R., 2002. Growth patterns and emplacement of the andesitic lava dome at Soufrière Hills Volcano, Montserrat. In: Druitt, T.H., Kokelaar, B.P. (Eds.), The Eruption of Soufriere Hills Volcano, Montserrat, from 1995 to 1999. Geol. Soc., London, Memoir 21, 115-152.

Widiwijayanti, C., Clarke, A., Elsworth, D., Voight, B., 2005. Geodetic constraints on the shallow magma system at Soufrière Hills Volcano, Montserrat, Geophys. Res. Lett. 32, L11309. doi:10.1029/2005GL022846.

Williams-Jones, G., Stix, J., Heiligmann, M., Barquero, J., Fernadez, E., Gonzalez, E.D., 2001. A model of degassing and seismicity at Arenal Volcano, Costa Rica. J. Volcanol. Geotherm. Res. $108,121-139$.

Wilson, L., 1980. Relationships between pressure, volatile content and ejecta velocity in three types of volcanic explosion. J. Volcanol. Geotherm. Res. 8, 297-313.

Woods, A.W., 1995. A model of vulcanian explosions. Nuclear Engineering Design 155, 345-357.

Wylie, J.J., Voight, B., Whitehead, J.A., 1999. Instability of magma flow from volatile-dependent viscosity. Science 285, 1883-1885.

Yokoo, A., Tameguri, T., Iguchi, M., 2009. Swelling of a lava plug associated with a Vulcanian eruption at Sakurajima Volcano, Japan, as revealed by infrasound record: case study of the eruption on January 2, 2007. Bull. Volcanol. 71, 619-630.

Young, S., Sparks, R., Aspinall, W., Lynch, L., Miller, A., Robertson, R., Shepherd, J., 1998. Overview of the eruption of Soufriere Hills Volcano, Montserrat, 18 July 1995 to December 1997. Geophys. Res. Lett. 25, 3389-3392.

Zobin, V.M., Melnik, O.E., Gonzalez, M., Macedo, O., Breton, M., 2010. Swarms of microearthquakes associated with the 2005 Vulcanian explosion sequence at Volcan de Colima, Mexico. Geophys. J. Internat. 182, 808-828. 


\section{Figure captions}

Figure 1: Schematic representation of the pre-explosive state of the magmatic column and symbols definition. Each sample of Table 1 is assumed to represent one horizontal slice of the column.

Figure 2: Constraints on the overpressures caused by column sealing and gas accumulation (Mechanism 1). The thin line represents a deep plug located below the heterogeneous zone of the magmatic column, and the bold line represents a shallow plug located below the dense cap. Overpressures are given with respect to the magmastatic gradient. Triangles are the tensile strength from each pressure slice (Burgisser et al., 2010). The gray area covers overpressures that are large enough to overcome the tensile strength of most samples and cover the depth and magnitude of the periodic source causing edifice deformation (black square). The inset illustrates the total pressure (magmastatic + overpressure) for each plug depth, respectively.

Figure 3: Overpressure profile with depth as a function of overpressure mechanism (1: gas accumulation, 2: wall elasticity, 3: microlite crystallization, and 4: conduit flow). Overpressures are given with respect to the magmastatic gradient. The black square covers the depth and magnitude of the periodic source causing edifice deformation. The red curves are Mechanism 1 and are identical to those of Fig. 2, the black curve is Mechanism 2, and the green curve is Mechanism 3. The three blue curves are Mechanism 4 and refer (from left to right at the greatest depth) to the model of Melnik and Sparks (2002), Hale and Mühlhaus (2007), and Hautmann et al. (2009), respectively. The light colored areas below the profiles of Mechanisms 1 and 4 represent possible values between extreme scenarios. The light colored areas below the profiles of Mechanisms 2 and 3 represent error propagation from the input data 
(Table 1). Error estimates for Mechanism 3 indicate that the irregularities of the overpressure profile are beyond measurement artifacts.

Figure 4: Overpressure profile with depth for microlite crystallization (Mechanism 3).

Overpressures are given with respect to lithostatic gradient. The light colored area represents error propagation from the input data (Table 1). The black square covers the depth and magnitude of the periodic source causing edifice deformation.

Figure 5: Bulk modulus of the wallrock with depth as a function of overpressure mechanism (1: gas accumulation, 2: wall elasticity, and 4: conduit flow). The light red area between the red curves (Mechanism 1) represents possible values between extreme scenarios. The black curve is Mechanism 2, and the blue curve (Mechanism 4) refers to the model of Hale and Mühlhaus (2007). The vertical dashed line represents the lowest value for wallrock elasticity at Soufrière Hills (Widiwijayanti et al., 2005).

Figure 6: Pre-explosive density profiles as a function of overpressure mechanism (1: gas accumulation, 2: wall elasticity, 3: microlite crystallization, and 4: conduit flow). Narrow columns on the left of each porosity profile code the quench (field) lithology of each slice. The three numbered zones correspond to regions of similar vesicularity (I. dense plug, II. heterogeneous zone, and III. homogeneous zone). The column 4a is only based on the model of Melnik and Sparks (2002) because the model of Hale and Mühlhaus (2007) yields quasi identical results. The column $4 \mathrm{~b}$ is based on the model of Hautmann et al. (2009).

Figure 7: Vertical expansion of each slice during a sudden release of the magmastatic overpressure as a function of overpressure mechanism (1: gas accumulation and 4: conduit flow). The percentage of vertical expansion corresponds to the change in thickness of each slice during explosion. The red curves are Mechanism 1 with a deep plug (1a), and the purple curves are Mechanism 1 with a shallow plug (1b). Black 
curves are Mechanism 4 and are only based on the model of Melnik and Sparks (2002) because curves given by the two other models are similar. For each mechanism, the gray areas represent possible values between the presence (solid lines) or the absence (dashed lines) of syn-explosive degassing.

Figure 8: Pre-explosive porosity as a function or pre-explosive pressure. The black line shows the porosities predicted by the conduit flow model of Clarke et al (2007). Data are from Table 1, and the analytical errors are from Burgisser et al. (2010).

Figure 9: Two end-member scenarios for a Vulcanian explosion. The left scenario is classic and depicts a magma column being evacuated by a fast moving fragmentation front with negligible expansion. The right scenario depicts a fast expanding magma column that feeds a quasi-steady fragmentation front. The insets show column expansion, starting from the over-pressurized profile in black and going back to magmastatic in successive lighter shades of gray representing expansion by gas density only, $50 \%$ syn-eruptive degassing, and 100\% degassing, respectively. The left inset corresponds to Mechanism 1 (gas accumulation, curves $1 \mathrm{~b}$ in Fig. 7) and the right inset corresponds to Mechanism 4 (conduit flow, curves 4 in Fig. 7). 
Table 1. Summary of the data used in the density profile reconstruction. Pre-explosive pressures $\left(P_{i}\right)$, quantities of exsolved water $\left(\alpha_{i}\right)$, dissolved water $\left(x_{i}\right)$, and microlite ( $\mu$ lite) were used as model input (data from Burgisser et al., 2010, and reference therein). Overpressures and depths (right) are model constraints and outputs for each pressurization mechanism, respectively. Microlite contents are bubble-free volume fraction, depths $(z)$ are in $\mathrm{m}$, and overpressures $\left(\Delta P_{i}\right)$ are in MPa.

\begin{tabular}{|c|c|c|c|c|c|c|c|c|c|c|c|c|c|c|c|}
\hline \multirow[t]{2}{*}{ Sample } & \multirow{2}{*}{$\begin{array}{c}P_{i} \\
\mathrm{MPa}\end{array}$} & \multirow{2}{*}{$\begin{array}{c}\alpha_{i} \\
\mathrm{vol} \%\end{array}$} & \multirow{2}{*}{$\begin{array}{c}x_{i} \\
\mathrm{ppm}\end{array}$} & \multirow{2}{*}{$\begin{array}{c}\mu l i t e \\
\text { vol } \%\end{array}$} & \multicolumn{3}{|c|}{ 1. Gas } & \multicolumn{2}{|c|}{ 2. Wall } & \multicolumn{2}{|c|}{ 3. Microlite } & \multicolumn{4}{|c|}{ 4. Flow } \\
\hline & & & & & $z$ & ${ }^{\mathrm{a}} \Delta P_{i}$ & ${ }^{\mathrm{b}} \Delta P_{i}$ & $z$ & $\Delta P_{i}$ & $z$ & $\Delta P_{i}$ & ${ }^{\mathrm{c}} Z$ & ${ }^{\mathrm{c}} \Delta P_{i}$ & $\mathrm{~d}_{Z}$ & ${ }^{\mathrm{d}} \Delta P_{i}$ \\
\hline AMO-35 & 0.4 & 3 & 10 & 51 & 17 & 0 & 0 & 15 & 0.0 & 5 & 0.1 & 0.02 & 0.4 & 0.001 & 0.4 \\
\hline AMO-40 & 0.7 & 6 & 35 & 46 & 29 & 0 & 0 & 27 & 0.1 & 10 & 0.2 & 0.1 & 0.7 & 0.005 & 0.7 \\
\hline 99306-1a2 & 0.9 & 6 & 39 & 24 & 37 & 0 & 0 & 33 & 0.1 & 18 & 0.5 & 0.2 & 0.8 & 0.01 & 0.9 \\
\hline AMO-34-D & 1.0 & 19 & 186 & 43 & 44 & 0 & 19.9 & 38 & 0.1 & 19 & 0.4 & 0.3 & 1.0 & 0.02 & 1.0 \\
\hline AMO-44-D & 1.1 & 3 & 26 & 41 & 47 & 0 & 19.8 & 42 & 0.1 & 23 & 0.4 & 0.3 & 1.1 & 0.02 & 1.1 \\
\hline $99305-34 p$ & 1.3 & 37 & 607 & 51 & 64 & 0 & 19.5 & 51 & 0.2 & 25 & 0.6 & 0.7 & 1.3 & 0.04 & 1.3 \\
\hline AMO-27 & 1.3 & 3 & 32 & 39 & 65 & 0 & 19.5 & 52 & 0.2 & 29 & 0.6 & 0.7 & 1.3 & 0.04 & 1.3 \\
\hline 99318-1a & 1.8 & 4 & 63 & 43 & 86 & 0 & 19.0 & 71 & 0.3 & 33 & 0.7 & 1.8 & 1.8 & 0.1 & 1.8 \\
\hline $99623-1 \mathrm{c}$ & 2.1 & 2 & 30 & 40 & 97 & 0 & 18.8 & 82 & 0.3 & 39 & 0.9 & 2.6 & 2.0 & 0.2 & 2.1 \\
\hline 99303-2 & 2.2 & 9 & 180 & 39 & 102 & 0 & 18.7 & 86 & 0.3 & 47 & 1.0 & 3.0 & 2.1 & 0.2 & 2.2 \\
\hline $99302-2$ & 2.3 & 22 & 527 & 38 & 108 & 0 & 18.5 & 91 & 0.3 & 56 & 1.3 & 3.5 & 2.2 & 0.3 & 2.3 \\
\hline AB1-D & 2.4 & 6 & 109 & 33 & 112 & 0 & 18.5 & 94 & 0.3 & 57 & 1.2 & 3.8 & 2.3 & 0.3 & 2.4 \\
\hline AMO-38-D & 2.6 & 14 & 344 & 34 & 123 & 0 & 18.2 & 103 & 0.4 & 66 & 1.4 & 5.0 & 2.5 & 0.4 & 2.6 \\
\hline $990302-7 \mathrm{a}$ & 2.8 & 16 & 440 & 34 & 134 & 0 & 18.0 & 112 & 0.4 & 74 & 1.6 & 6.2 & 2.7 & 0.6 & 2.8 \\
\hline 990329-1a & 3.0 & 35 & 1292 & 33 & 145 & 0 & 17.8 & 118 & 0.5 & 78 & 2.0 & 7.4 & 2.9 & 0.7 & 3.0 \\
\hline AMO-42 & 3.1 & 24 & 764 & 35 & 148 & 0 & 17.8 & 120 & 0.5 & 85 & 1.8 & 7.6 & 2.9 & 0.7 & 3.0 \\
\hline 990329-2a & 3.2 & 70 & 5917 & 32 & 167 & 0 & 17.6 & 126 & 0.6 & 96 & 2.6 & 8.7 & 3.0 & 0.8 & 3.2 \\
\hline $99305-33 p$ & 3.4 & 16 & 526 & 31 & 177 & 0 & 17.4 & 134 & 0.7 & 99 & 2.0 & 10 & 3.2 & 1.0 & 3.4 \\
\hline AMO-43 & 3.7 & 16 & 565 & 22 & 190 & 0 & 17.2 & 143 & 0.7 & 125 & 2.6 & 12 & 3.4 & 1.3 & 3.6 \\
\hline BCP-3-cr & 3.8 & 3 & 92 & n.a. & 195 & 0 & 17.1 & 148 & 0.7 & n.a. & n.a. & 13 & 3.5 & 1.4 & 3.7 \\
\hline $990329-3 c$ & 3.9 & 56 & 3801 & 29 & 204 & 0 & 17.0 & 152 & 0.8 & 136 & 3.0 & 14 & 3.6 & 1.5 & 3.8 \\
\hline $990329-4 b$ & 4.1 & 64 & 5733 & 28 & 235 & 0 & 16.7 & 162 & 1.0 & 148 & 3.4 & 17 & 3.8 & 1.9 & 4.1 \\
\hline 99305-3 & 5.1 & 51 & 4118 & 25 & 319 & 0 & 15.7 & 202 & 1.5 & 149 & 4.2 & 30 & 4.7 & 3.9 & 5.1 \\
\hline AB2-D & 5.2 & 5 & 210 & 30 & 322 & 0 & 15.6 & 205 & 1.5 & 158 & 3.0 & 31 & 4.7 & 4.1 & 5.2 \\
\hline 99306-1a1 & 5.6 & 9 & 455 & 64 & 338 & 0 & 15.3 & 218 & 1.6 & 203 & 1.7 & 36 & 5.0 & 5.0 & 5.5 \\
\hline $99323-1 c$ & 5.6 & 22 & 1212 & 24 & 338 & 0 & 15.3 & 218 & 1.6 & 210 & 4.0 & 36 & 5.0 & 5.0 & 5.5 \\
\hline $990329-3 b$ & 6.0 & 56 & 5963 & 23 & 382 & 0 & 14.8 & 236 & 1.8 & 229 & 5.1 & 44 & 5.4 & 6.5 & 5.9 \\
\hline BCP-4-cr & 6.2 & 3 & 150 & 37 & 387 & 0 & 14.7 & 241 & 1.8 & 245 & 2.9 & 46 & 5.4 & 7.0 & 6.0 \\
\hline BCP1-cr & 6.5 & 4 & 193 & 31 & 404 & 0 & 14.3 & 256 & 1.9 & 261 & 3.6 & 52 & 5.7 & 8.4 & 6.4 \\
\hline $990302-5 a$ & 7.2 & 42 & 4005 & 21 & 449 & 0 & 13.7 & 282 & 2.2 & 315 & 5.9 & 65 & 6.2 & 11 & 7.0 \\
\hline 990302-6a & 7.2 & 36 & 3205 & 21 & 449 & 0 & 13.7 & 282 & 2.2 & 356 & 5.8 & 65 & 6.2 & 11 & 7.0 \\
\hline $990302-7 b$ & 7.2 & 42 & 4118 & 21 & 449 & 0 & 13.7 & 282 & 2.2 & 356 & 5.9 & 65 & 6.2 & 11 & 7.0 \\
\hline AMO-29 & 8.1 & 32 & 3068 & 32 & 508 & 0 & 12.7 & 319 & 2.5 & 365 & 5.8 & 85 & 6.8 & 17 & 7.9 \\
\hline $990329-3 a$ & 8.7 & 50 & 6785 & 19 & 554 & 0 & 12.2 & 341 & 2.8 & 366 & 7.5 & 99 & 7.2 & 21 & 8.4 \\
\hline BCP2-cr & 9.1 & 3 & 221 & 36 & 570 & 0 & 11.8 & 356 & 2.8 & 378 & 4.5 & 107 & 7.4 & 23 & 8.7 \\
\hline $990329-4 a$ & 9.6 & 39 & 4795 & 18 & 608 & 7.4 & 11.2 & 378 & 3.1 & 494 & 8.2 & 121 & 7.7 & 28 & 9.2 \\
\hline AMO-44-V & 9.7 & 24 & 2355 & 38 & 614 & 7.3 & 11.1 & 382 & 3.1 & 506 & 6.1 & 124 & 7.8 & 29 & 9.3 \\
\hline AMO-30 & 11.2 & 22 & 2437 & 23 & 692 & 5.9 & 9.6 & 440 & 3.5 & 533 & 8.4 & 162 & 8.5 & 43 & 10.5 \\
\hline AMO-32 & 11.8 & 21 & 2437 & 21 & 721 & 5.3 & 9.1 & 461 & 3.6 & 537 & 9.1 & 177 & 8.8 & 50 & 10.9 \\
\hline SP1-D & 12.4 & 16 & 1814 & 34 & 752 & 4.7 & 8.4 & 486 & 3.7 & 539 & 7.8 & 194 & 9.1 & 58 & 11.4 \\
\hline AB1-V & 12.7 & 21 & 2666 & 35 & 767 & 4.4 & 8.2 & 497 & 3.8 & 547 & 8.3 & 202 & 9.2 & 61 & 11.6 \\
\hline AMO-34-V & 13.6 & 18 & 2355 & 39 & 813 & 3.5 & 7.3 & 533 & 4.0 & 579 & 8.3 & 229 & 9.6 & 74 & 12.3 \\
\hline $990329-1 b$ & 13.7 & 30 & 4500 & 15 & 817 & 3.4 & 7.2 & 536 & 4.0 & 648 & 11.7 & 231 & 9.6 & 75 & 12.3 \\
\hline AB2-V & 15.4 & 16 & 2355 & 30 & 903 & 1.7 & 5.4 & 604 & 4.4 & 724 & 10.4 & 286 & 10.3 & 102 & 13.5 \\
\hline SP1-V & 20.7 & 16 & 3003 & 23 & 1163 & 0 & 0.2 & 811 & 5.5 & 913 & 15.6 & 476 & 11.7 & 207 & 16.7 \\
\hline $990302-6 b$ & 24.7 & 24 & 6214 & 11 & 1384 & 0 & 0 & 970 & 6.6 & 1038 & 22.2 & 660 & 12.4 & 311 & 18.8 \\
\hline
\end{tabular}




\begin{tabular}{|c|c|c|c|c|c|c|c|c|c|c|c|c|c|c|c|}
\hline AMO-38-V & 26.0 & 11 & 2617 & 27 & 1442 & 0 & 0 & 1018 & 6.8 & 1255 & 18.2 & 712 & 12.5 & 343 & 19.3 \\
\hline $\mathrm{AMO} 3 \mathrm{C}$ & 28.2 & 13 & 3278 & 19 & 1547 & 0 & 0 & 1105 & 7.2 & 1259 & 22.3 & 809 & 12.6 & 404 & 20.3 \\
\hline PV3 & 29.6 & 14 & 3795 & 16 & 1617 & 0 & 0 & 1162 & 7.5 & 1366 & 24.5 & 875 & 12.7 & 446 & 20.8 \\
\hline AMO-26 & 30.4 & 17 & 4795 & 20 & 1658 & 0 & 0 & 1193 & 7.7 & 1370 & 24.5 & 913 & 12.8 & 471 & 21.2 \\
\hline AMO6A-2 & 38.6 & 11 & 3698 & 14 & 2038 & 0 & 0 & 1514 & 8.9 & 1747 & 32.6 & 1284 & 13.0 & 725 & 23.9 \\
\hline MT06-04 & 46.6 & 11 & 4500 & 17 & 2410 & 0 & 0 & 1827 & 10.2 & 2014 & 38.4 & 1654 & 13.0 & 998 & 26.0 \\
\hline \multirow{2}{*}{ AMO6A-1 } & 48.5 & 9 & 3897 & 19 & 2497 & 0 & 0 & 1902 & 10.5 & 2028 & 38.7 & 1741 & 13.0 & 1065 & 26.4 \\
\hline & 52.2 & 7 & 3003 & 22 & 2661 & 0 & 0 & 2047 & 10.9 & 2064 & 39.5 & 1905 & 13.0 & 1195 & 27.2 \\
\hline $\begin{array}{l}\text { AMO-33 } \\
\text { AMO3D }\end{array}$ & 59.4 & 8 & 4238 & 12 & 2988 & 0 & 0 & 2330 & 11.9 & 2618 & 51.7 & 2230 & 13.1 & 1460 & 28.6 \\
\hline & 61.4 & 7 & 3434 & 12 & 3076 & 0 & 0 & 2408 & 12.1 & 2680 & 53.1 & 2318 & 13.1 & 1534 & 28.9 \\
\hline $\begin{array}{l}\text { MT06-03 } \\
\text { AMO-9 }\end{array}$ & 85.1 & 7 & 4643 & 11 & 4126 & 0 & 0 & 3337 & 14.8 & 3666 & 75.4 & 3359 & 13.3 & 2454 & 31.8 \\
\hline \multicolumn{16}{|c|}{ n.a.: not analyzed. } \\
\hline \multicolumn{16}{|c|}{ a deep plug. } \\
\hline \multicolumn{16}{|c|}{ b shallow plug. } \\
\hline${ }^{\mathrm{c}} \mathrm{fr}$ & & & & & del. & & & & & & & & & & \\
\hline${ }^{d} \mathrm{fr}$ & al & & & & & & & & & & & & & & \\
\hline
\end{tabular}

Table 2: Regression coefficients used to calculate overpressure and porosity distributions from conduit flow model runs.

\begin{tabular}{|c|c|c|c|c|}
\hline Variable & $\varepsilon$ & $\delta$ & $\gamma$ & $\mathrm{R}^{2}$ \\
\hline \multicolumn{5}{|c|}{ Melnik and Sparks (2002) } \\
\hline$\Delta P_{l}(z)$ & $1.94910^{10}$ & $5.7210^{-5}$ & 1.324 & 0.99 \\
\hline$\alpha(z)$ & 612.2 & $4.25810^{-4}$ & 1.093 & 0.99 \\
\hline \multicolumn{5}{|c|}{ Clarke et al. (2007) } \\
\hline$\alpha\left(P_{i}\right)$ & 15.89 & $10^{-3}$ & 2.458 & 0.82 \\
\hline \multicolumn{5}{|c|}{ Hale and Mühlhaus (2007) } \\
\hline$\Delta P_{i}(\mathrm{z})$ & $2.9510^{11}$ & $4.6510^{-6}$ & 1.30 & 0.91 \\
\hline \multicolumn{5}{|c|}{ Hautmann et al. (2009) } \\
\hline$\Delta P_{i}(\mathrm{z})$ & $1.310^{12}$ & $2.010^{-6}$ & 1.30 & 0.97 \\
\hline
\end{tabular}


Table 3: Some volcanoes displaying episodic Vulcanian behavior. Four mechanisms of pressure buildup are listed (1: gas accumulation, 2: wall elasticity, 3: microlite crystallization, and 4: conduit flow), along with likely sealing mechanisms, relative frequency of explosion during an eruptive phase, the time the conduit has been active and the typical conduit repose time between eruptive phases.

\begin{tabular}{|c|c|c|c|c|c|c|c|c|}
\hline \multirow[b]{2}{*}{ Volcano $^{a}$} & \multicolumn{4}{|c|}{ Pressure buildup mechanism } & \multirow[b]{2}{*}{ Plug } & \multirow[b]{2}{*}{$\begin{array}{l}\text { Conduit } \\
\text { age }^{\mathrm{b}}(\mathrm{yr})\end{array}$} & \multirow[b]{2}{*}{$\begin{array}{l}\text { Repose } \\
\text { time }^{\mathrm{b}}(\mathrm{yr})\end{array}$} & \multirow[b]{2}{*}{ Explosions } \\
\hline & $\begin{array}{l}\text { 1: } \\
\text { gas }\end{array}$ & $\begin{array}{l}\text { 2: } \\
\text { wall }\end{array}$ & $\begin{array}{l}\text { 3: } \\
\text { microlite }\end{array}$ & $\begin{array}{l}\text { 4: } \\
\text { flow }\end{array}$ & & & & \\
\hline Arenal & $\mathrm{x}$ & $\mathrm{x}$ & & $\mathrm{x}$ & wallrock/overflow & 32 & $\sim 42$ & few \\
\hline Colima & $\mathrm{x}$ & & $\mathrm{x}$ & $\mathrm{x}$ & wallrock/magma plug & 13 & $\sim 3$ & many \\
\hline Galeras & $\mathrm{x}$ & & $\mathrm{x}$ & & wallrock/hydrothermal & 4 & 100 & few \\
\hline Lascar & $\mathrm{x}$ & & & & wallrock/hydrothermal & 1 & $\sim 5$ & few \\
\hline Montserrat & $\mathrm{x}$ & $\mathrm{x}$ & & $\mathrm{x}$ & magma plug & 2 & $>300$ & many \\
\hline Ngauruhoe & $\mathrm{x}$ & & & & wallrock/magma plug & 2 & $\sim 5$ & few \\
\hline Sakurajima & $\mathrm{x}$ & & & & magma plug & 50 & $<20$ & many \\
\hline
\end{tabular}

${ }^{a}$ Arenal: Williams-Jones et al. (2001), Soto and Alvarado (2006); Colima: Savov et al. (2008), Varley et al. (2010a, 2010b), Zobin et al., (2010); Galeras: Stix et al. (1997); Lascar: Matthews et al. (1997); Montserrat: this study; Ngauruhoe: Nairn and Self (1978), Hobden et al. (2002); Sakurajima: Iguchi et al. (2008), Yokoo et al. (2009).

${ }^{\mathrm{b}}$ from Siebert and Simkin (2002-2010).

${ }^{\mathrm{c}}$ Explosions were qualified of "few" when less than a dozen occurred during an eruptive phase and of "many" when they added to several dozens to several thousands. 


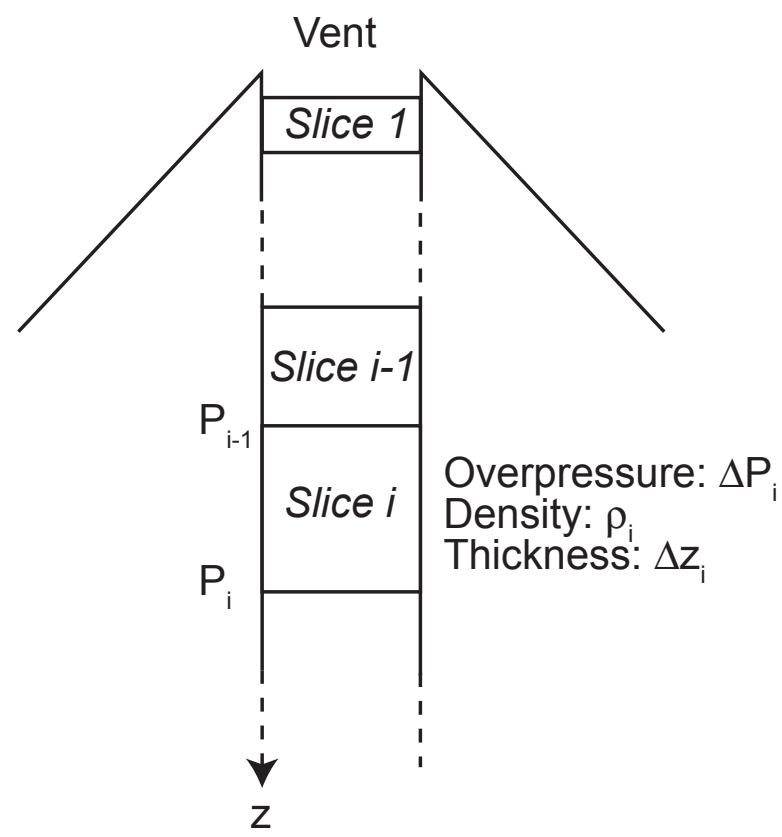

FIGURE 1 


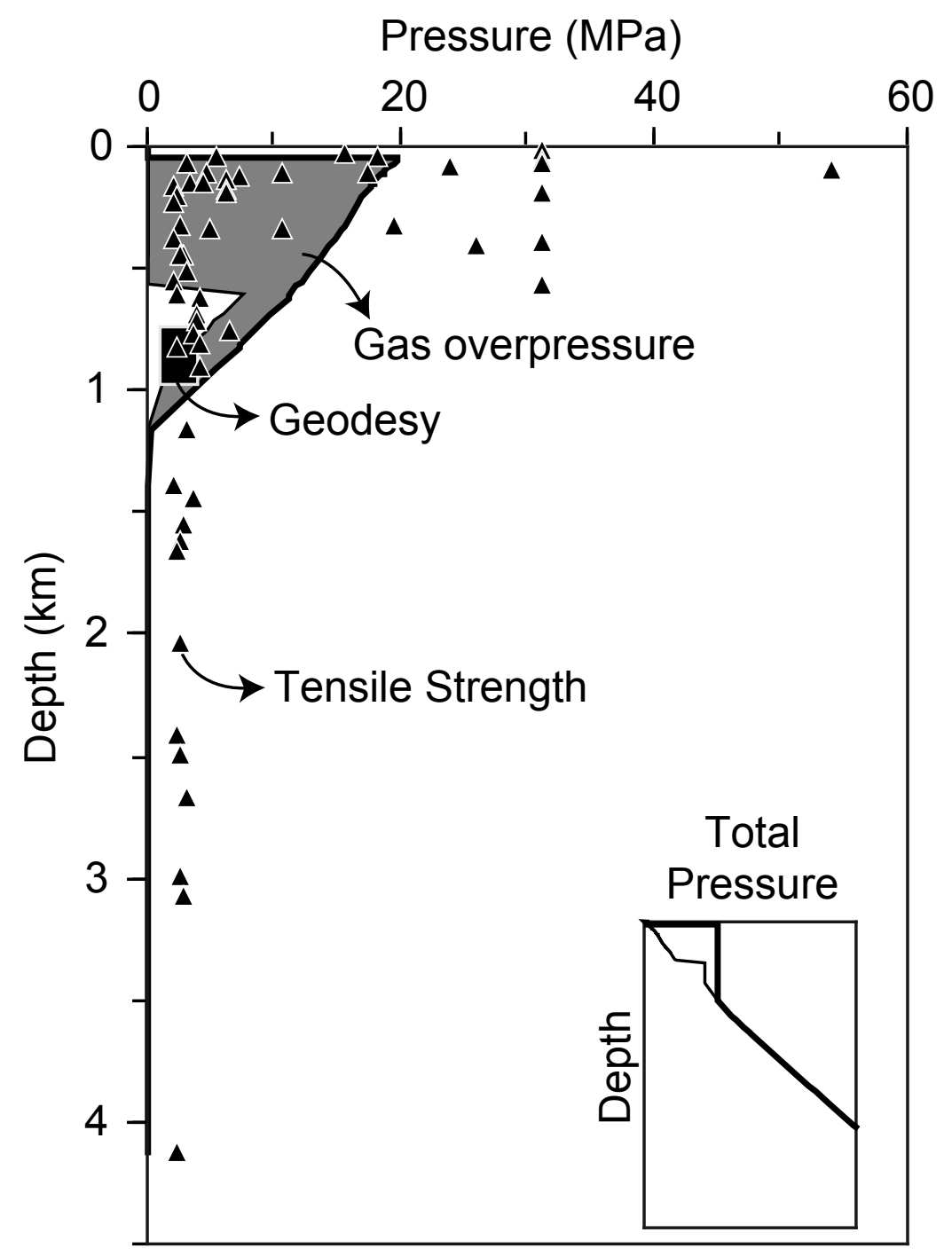

FIGURE 2 


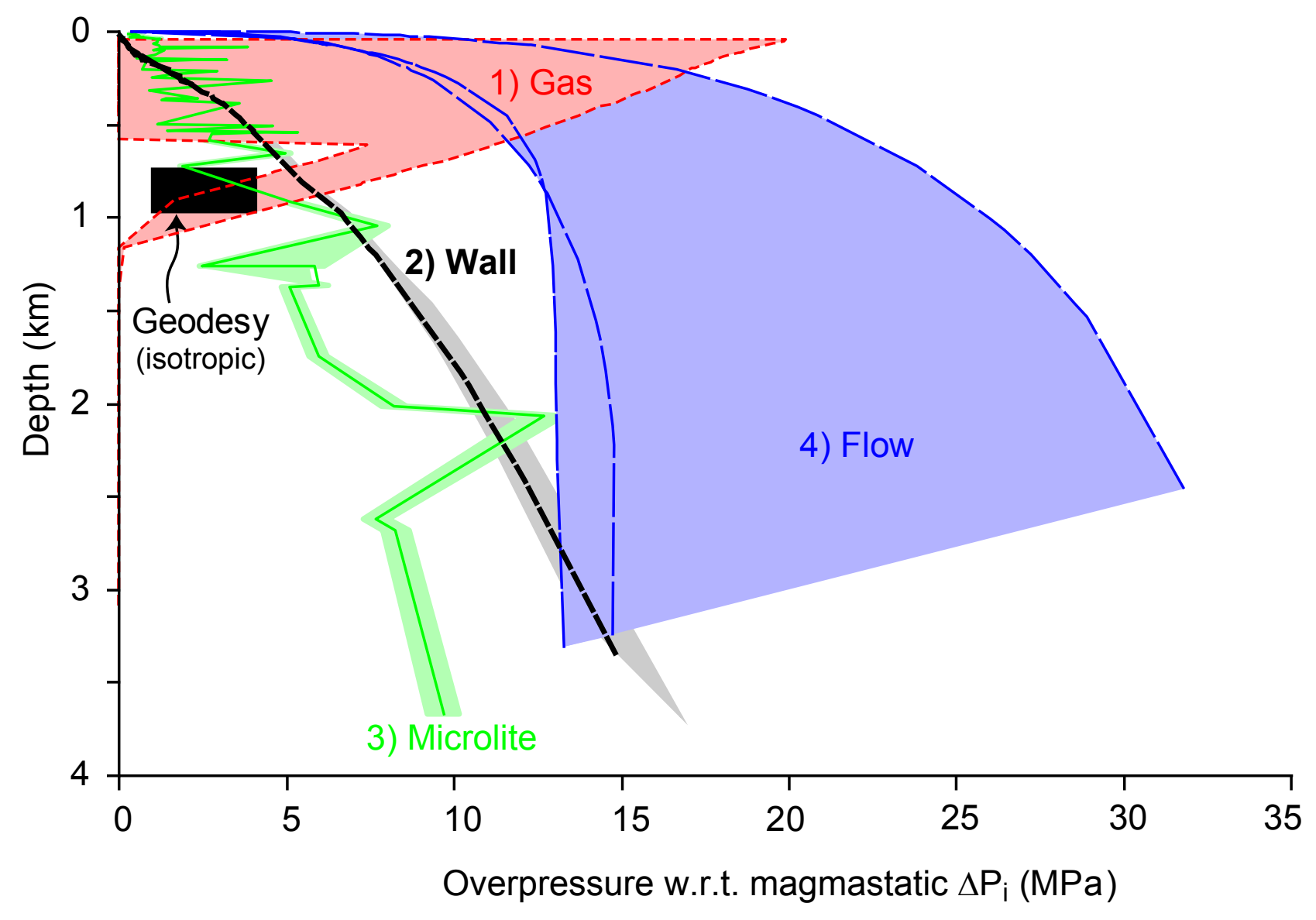

FIGURE 3 


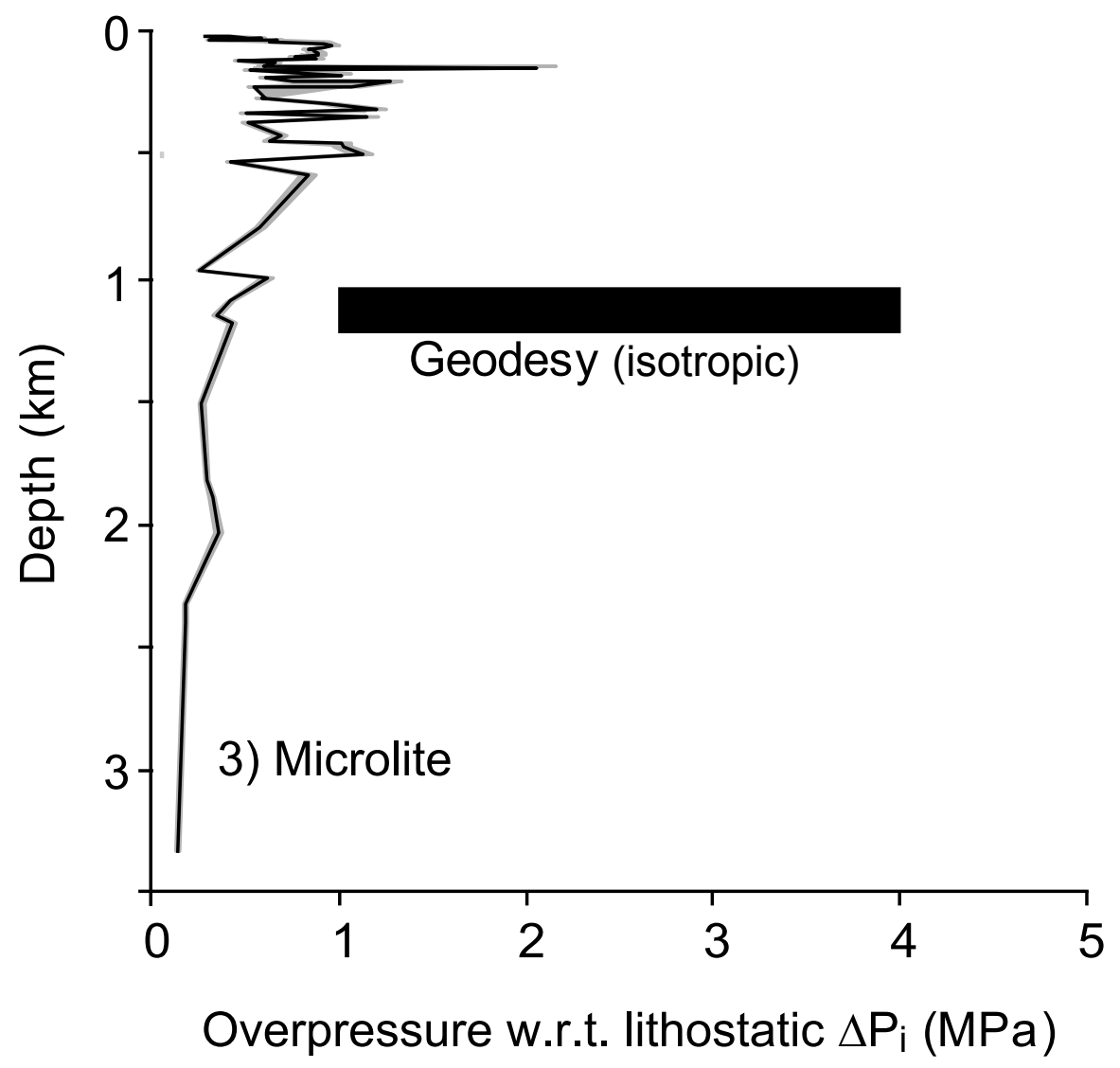

FIGURE 4 


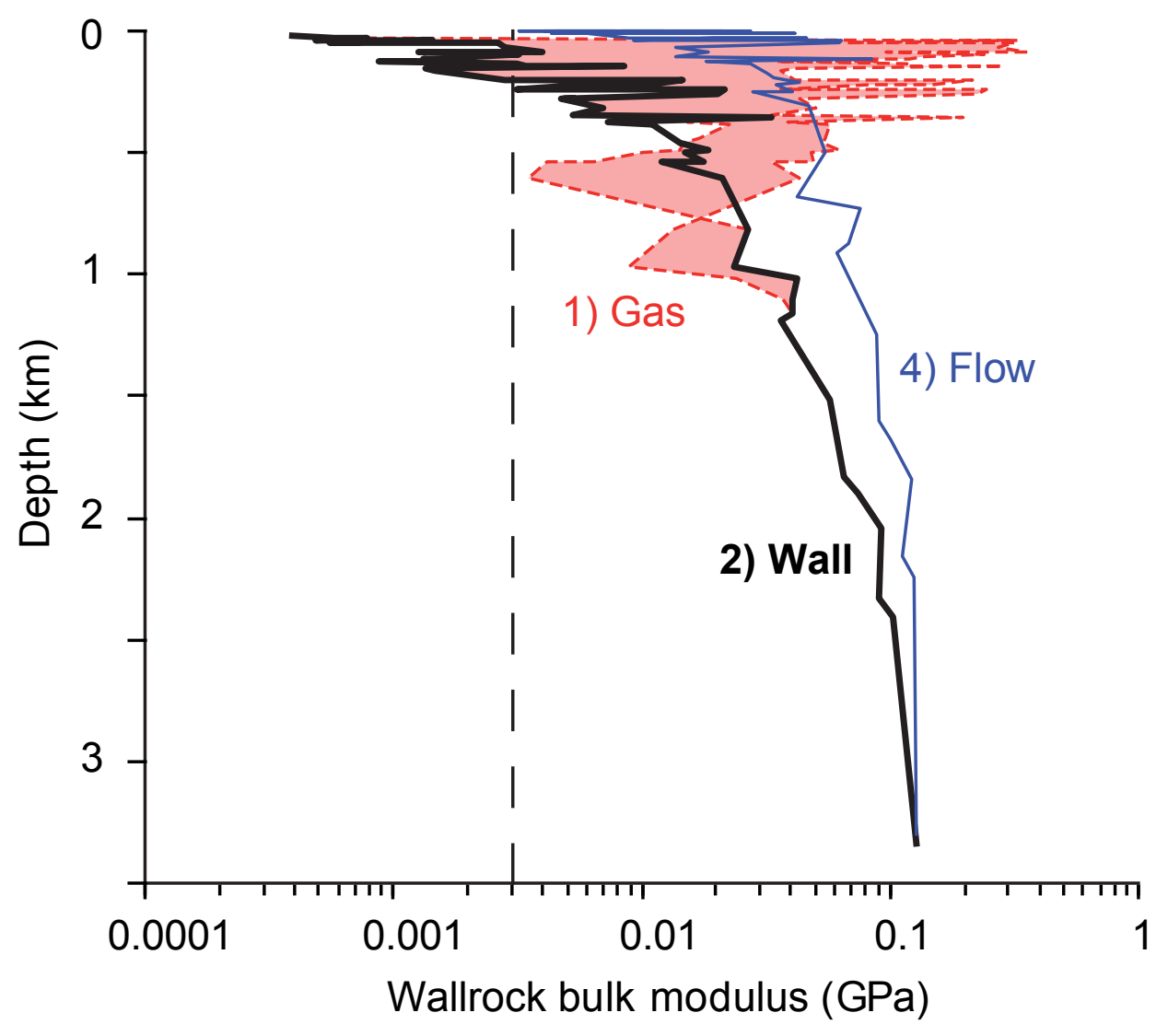

FIGURE 5 


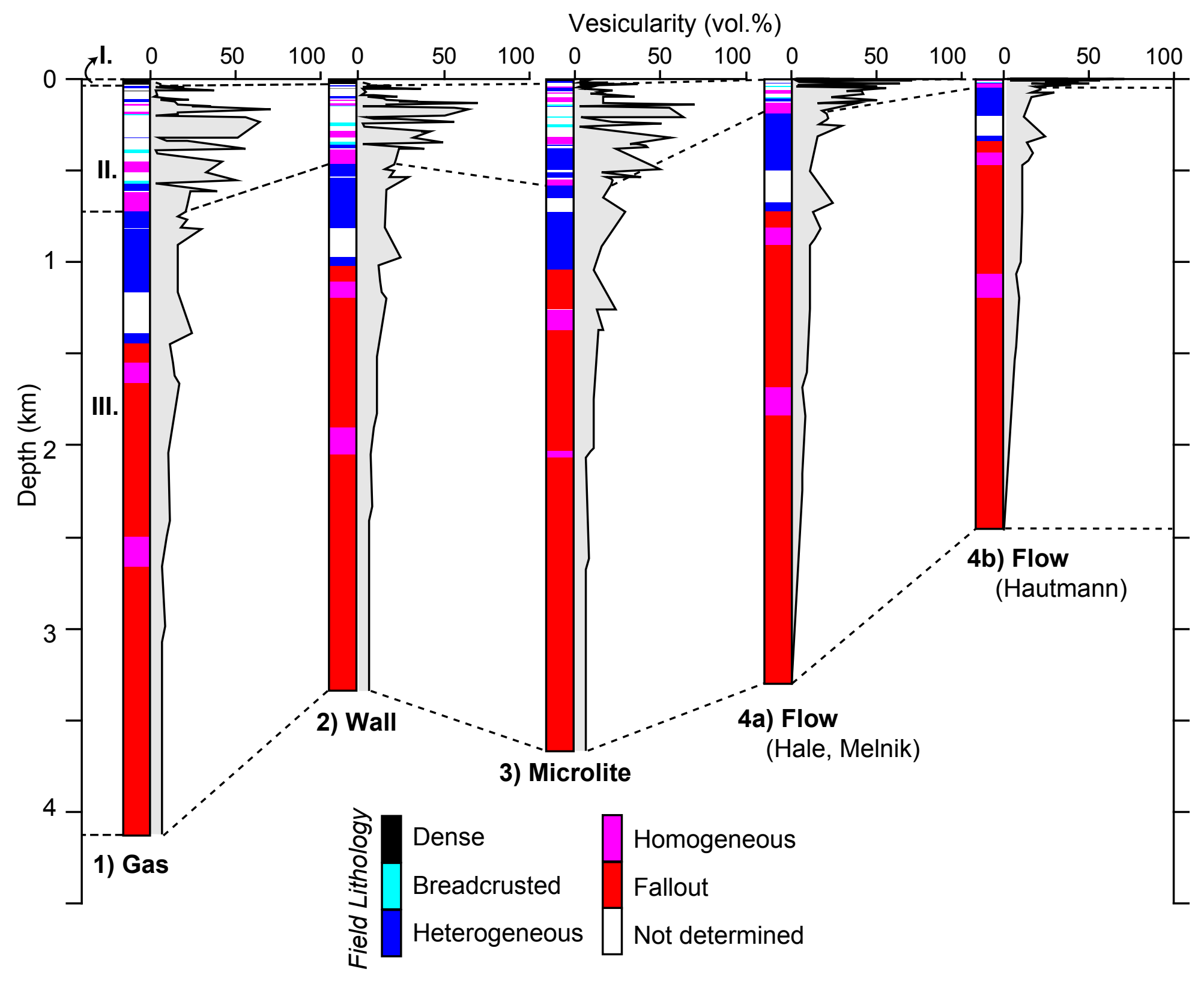

FIGURE 6 


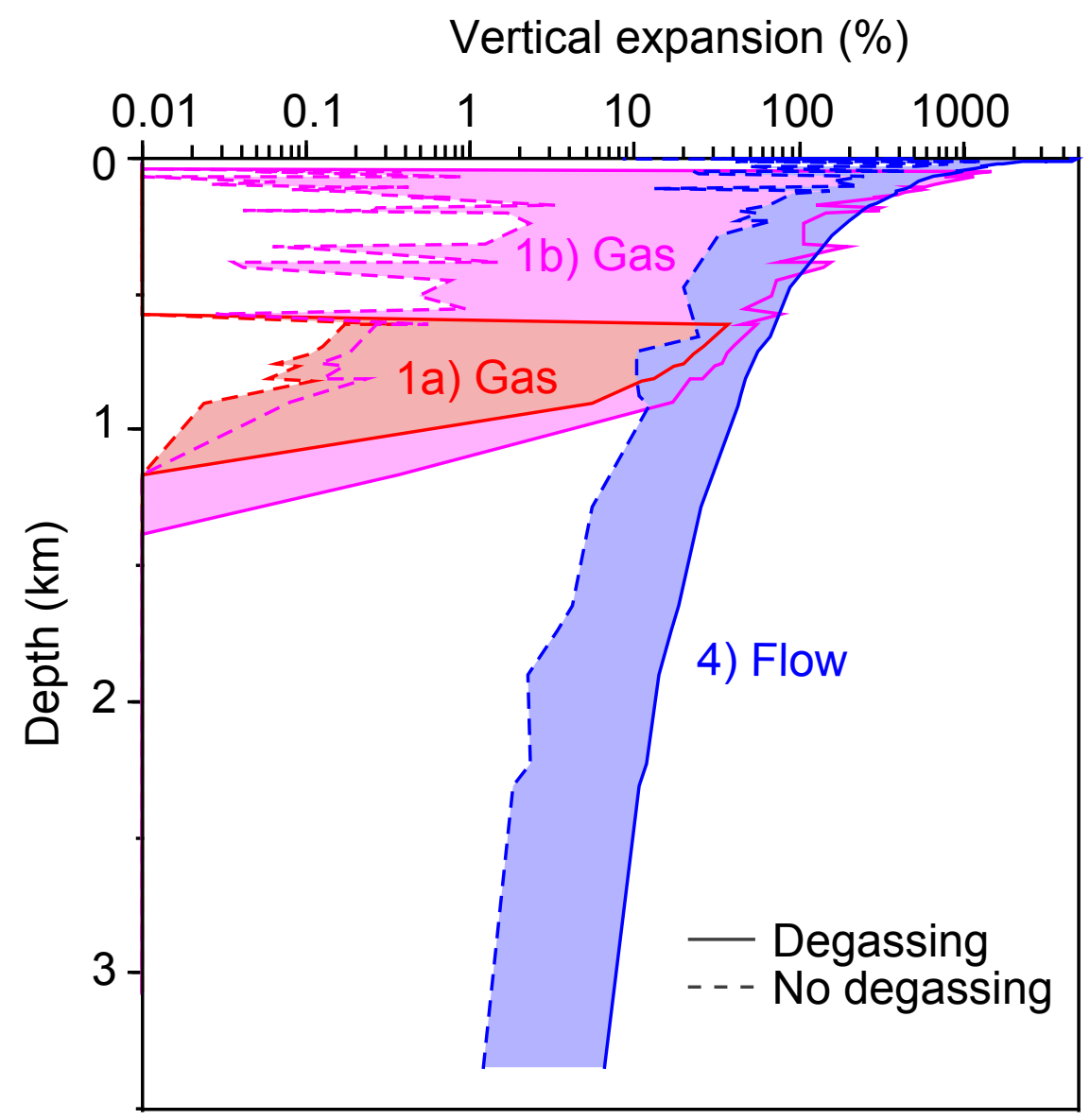

FIGURE 7 


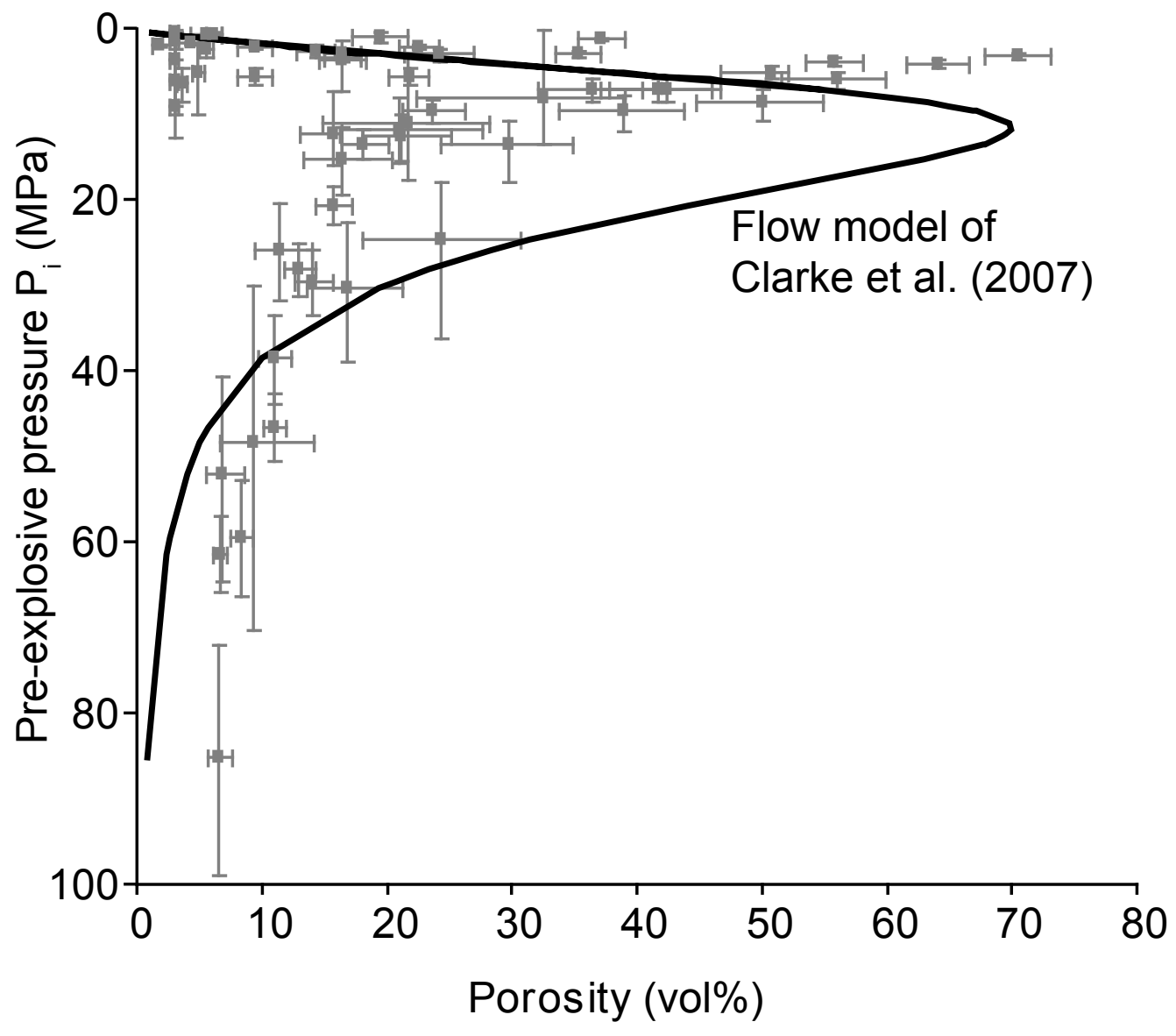

FIGURE 8 


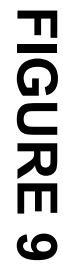

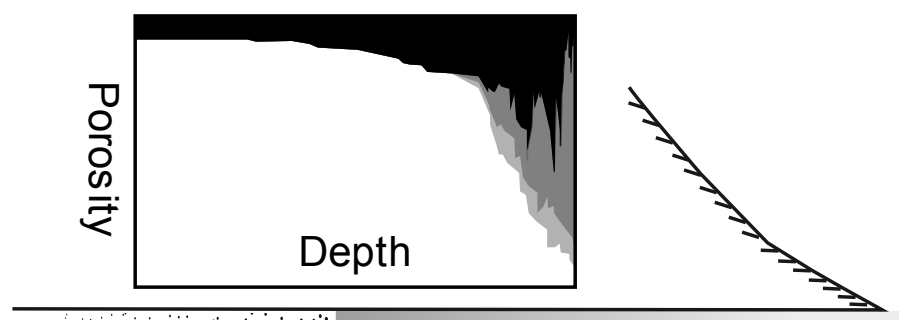

Fragmentation

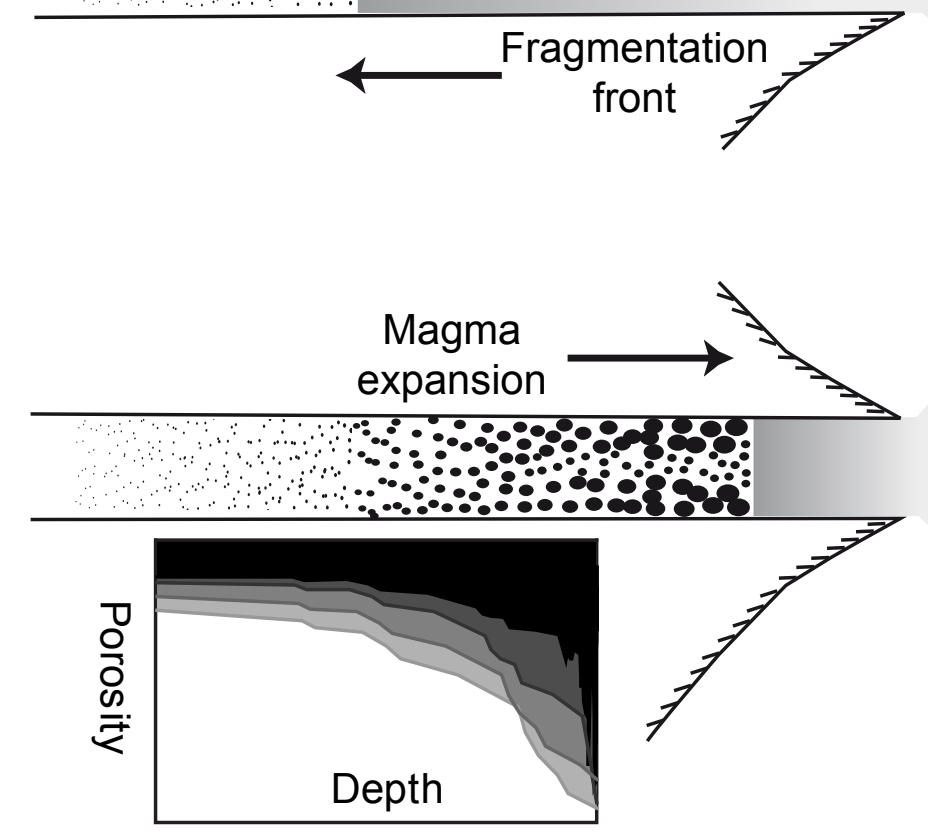

